\title{
Technical Report on Preliminary Methodology for Enhancing Risk Monitors with Integrated Equipment Condition Assessment
}
P Ramuhalli
JB Coble
GA Coles
EH Hirt

September 2013

Pacific Northwest

NATIONAL LABORATORY

Proudly Operated by Battelle Since 1965 


\title{
DISCLAIMER
}

This report was prepared as an account of work sponsored by an agency of the United States Government. Neither the United States Government nor any agency thereof, nor Battelle Memorial Institute, nor any of their employees, makes any warranty, express or implied, or assumes any legal liability or responsibility for the accuracy, completeness, or usefulness of any information, apparatus, product, or process disclosed, or represents that its use would not infringe privately owned rights. Reference herein to any specific commercial product, process, or service by trade name, trademark, manufacturer, or otherwise does not necessarily constitute or imply its endorsement, recommendation, or favoring by the United States Government or any agency thereof, or Battelle Memorial Institute. The views and opinions of authors expressed herein do not necessarily state or reflect those of the United States Government or any agency thereof.

\author{
PACIFIC NORTHWEST NATIONAL LABORATORY \\ operated by \\ BATTELLE \\ for the \\ UNITED STATES DEPARTMENT OF ENERGY \\ under Contract DE-AC05-76RL01830 \\ Printed in the United States of America \\ Available to DOE and DOE contractors from the \\ Office of Scientific and Technical Information, \\ P.O. Box 62, Oak Ridge, TN 37831-0062; \\ ph: (865) 576-8401 \\ fax: (865) 576-5728 \\ email: reports@adonis.osti.gov

\footnotetext{
Available to the public from the National Technical Information Service,

U.S. Department of Commerce, 5285 Port Royal Rd., Springfield, VA 22161

ph: (800) 553-6847

fax: (703) 605-6900

email: orders@ntis.fedworld.gov

online ordering: http://www.ntis.gov/ordering.htm
}

This document was printed on recycled paper.

$(9 / 2003)$ 


\section{Technical Report on Preliminary Methodology for Enhancing Risk Monitors with Integrated Equipment Condition Assessment}

P Ramuhalli

JB Coble ${ }^{(a)}$

GA Coles

EH Hirt

September 2013

Prepared for

U.S. Department of Energy

Contract DE-AC05-76RL01830

Pacific Northwest National Laboratory

Richland, Washington 99352

(a) University of Tennessee

Knoxville, Tennessee 37923 



\section{Executive Summary}

Advanced small modular reactors (AdvSMRs) may provide a longer-term alternative to traditional light-water reactors and SMRs based on integral pressurized water reactor concepts currently being considered. AdvSMRs are designed to incorporate multiple modules (which may or may not have shared components and structures) at a single location, comprising a full "plant." AdvSMR operation differs fundamentally from full-size plants because the smaller plants may be used for load-following or peakdemand power generation, instead of baseload generation. AdvSMRs are also being considered for dualuse, where process heat would be used for both electricity generation and another purpose such as hydrogen production or water desalination, shown in Figure ES.1.

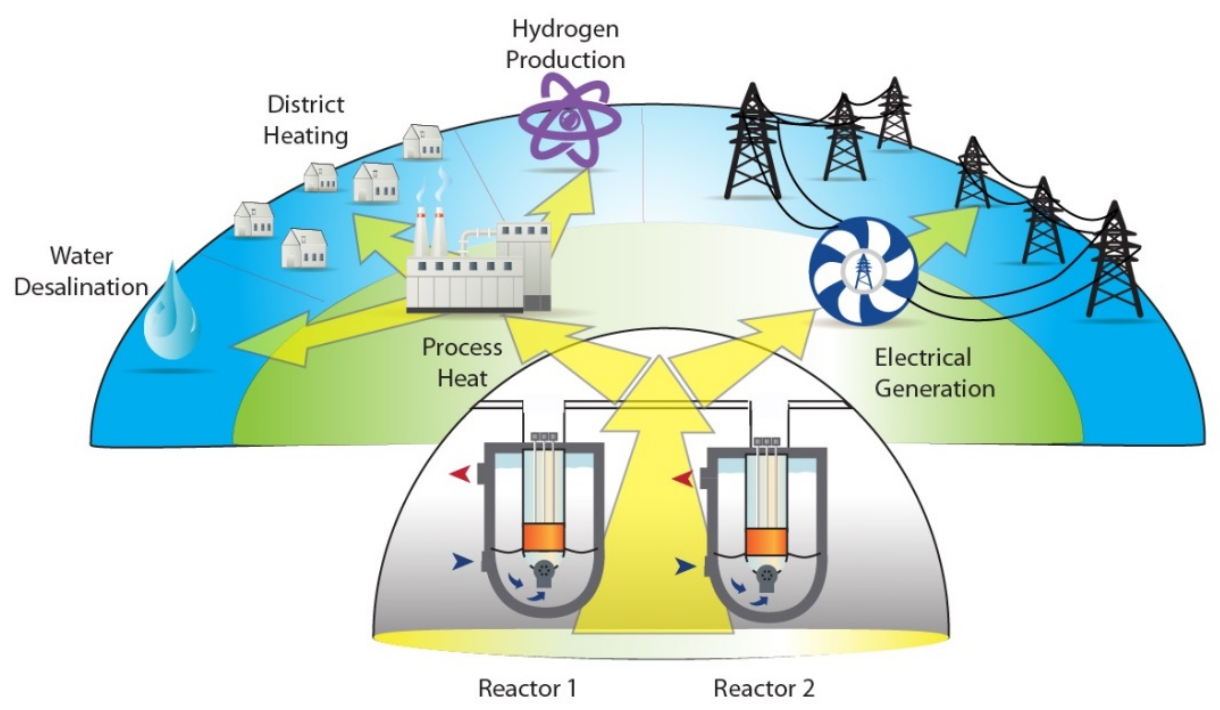

Figure ES.1. In Proposed AdvSMRs, Multiple Reactor Modules may be Co-located to Support Common Electrical Generation and Process Heat Applications

Enhancing affordability of AdvSMRs will be critical to ensuring wider deployment. Although some of the loss of economies of scale inherent to AdvSMRs can be recovered, controllable day-to-day costs of AdvSMRs will be dominated by operation and maintenance (O\&M) costs.

Technologies that help characterize real-time risk are important to controlling O\&M costs and improving affordability of AdvSMRs. Given the possibility of frequently changing plant configurations in AdvSMRs, advanced plant configuration information, equipment condition information, and risk monitors are needed to support real-time decisions on O\&M. For this purpose, approaches are needed to integrate these three elements in a manner that provides a measure of risk that is customized for each AdvSMR unit, and accounts for the specific operational history of the unit. By integrating technologies for condition assessment with risk monitors, asset optimization and improved economics of AdvSMRs may be enabled by:

- Maximizing generation by assessing the potential impact of taking key components offline for testing or maintenance, 
- Supporting reduced O\&M staff by aiding in optimization of O\&M planning (specifically by assessing the contribution of individual components to changes in risk and using this information for scheduling maintenance activities),

- Enabling real-time decisions on stress-relief for risk-significant equipment susceptible to degradation and damage, and

- Supporting potential remote siting by providing early warning of potential increases in plant risk.

This report describes research results from an initial methodology for such enhanced risk monitors (ERMs) that integrate real-time information about equipment condition and probability of failure (POF) into risk monitors to provide an assessment of dynamic risk as plant equipment ages. This integration occurs at the level of the POF within risk monitors.

Risk monitors extend probabilistic risk assessment (PRA) frameworks by incorporating the actual and dynamic plant configuration (e.g., equipment availability, operating regimes, and environmental conditions) into the risk assessment. PRA is itself a systematic safety analysis methodology that follows four steps: identify undesirable consequences (e.g., reactor unavailability, core damage) and initiating events that can lead to these consequences; systematically identify accident sequences (defined by event trees and fault trees) through which the facility can move from the initiating event to the undesired consequence; calculate the probability of occurrence for each accident sequence; and rank the accident sequences according to probability of occurrence (or, alternatively, contribution to the undesirable event) to manage the major contributors to risk.

For Level 1 PRA models and associated risk monitors (which is the focus of the present work), the frequency of accidents that can cause core damage (called core damage frequency or CDF) is the risk metric that is typically used. Importance analysis is generally performed on the results of a PRA and provides a quantitative perspective on risk and sensitivity of risk to changes in input values.

Time-independence of component failures is assumed in traditional PRA modeling, and PRA component failure rates are typically assumed to be static over the life of the component. Changes (i.e., degradation) in the failure rate of a component that might be expected to normally occur over the component life are not explicitly represented.

The proposed methodology for ERM addresses this specific issue, and begins by defining PRA models that include all relevant components (based on failure modes and effects analysis that accounts for all potential operating conditions) and interdependencies between different modules of AdvSMRs. For each of the relevant components, equipment condition assessment (ECA) methods are deployed to monitor the condition of the equipment and the surrounding environment. This information is used by a prognostic algorithm to predict the probability of failure (POF) at a specified future time given the current condition of the component. As additional measurements become available (for instance, at successive time instants), the predictions may be improved by making use of updated condition information.

The component-specific time-dependent failure information (POF and confidence bounds) computed by the prognostics algorithm is then integrated into the PRA model, and the PRA model is solved to provide a time-dependent risk measure (such as CDF variation with time). 
Preliminary results of integrating time-dependent component POF into a simplified risk monitor for a simplified model of a liquid-metal-cooled AdvSMR design are described in this report, and used to identify key areas for further development of the ERM methodology.

The simplified model of an AdvSMR is intended to be prototypical and resembles proposed liquidmetal-cooled SMR designs. The design is defined at a simple level of abstraction but contains enough resolution and specific design elements to inform the development of a probabilistic risk assessment (PRA) model that, when quantified, produces a cogent set of results.

Initial evaluation of the ERM using the simplified model of the AdvSMR incorporated typical timebased event and failure probabilities for each of the initiating events and key components failures of the simplified AdvSMR power block design. These time-based likelihoods assume that the probability of failure grows from the initial probability when equipment is in like-new condition to a maximum probability of failure, which occurs before a scheduled maintenance action that restores or repairs the component to "as-new" condition. Periodic maintenance intervals are staggered for each component to reflect different operating lifetimes. Data for this evaluation was obtained from component failure and event data compiled by the nuclear power industry. This information (which is population-based averages) was used as the failure probability for new (or like-new) components in the PRA model for the simplified AdvSMR design. For components in the simplified design where such data was not available, nominal values based on operational experience from advanced reactors (and similar components used in operating reactors) was used to initialize the failure probabilities.

Using the enhanced risk monitor for the simplified AdvSMR design, with the associated time-based component failure information, we computed and analyzed the changes in CDF over time. The results indicate that, using the proposed framework for ERM, as the failure probabilities and failure rates change over time, the CDF changes over time. Repairs or replacements (bringing the components to as-new condition) reduce the risk, although aging of other components may still drive the overall risk higher. This information, when compared to traditional PRA analysis, appears to provide useful information for scheduling maintenance activities based on actual degradation condition and consequent failure probabilities. The results of traditional importance analysis indicate that, in cases where the risk measure (such as CDF) changes with time, alternate measures of importance are needed to better rank the components according to risk and to identify key contributors to the overall risk.

One observation from this analysis was that, using available component failure data but without the time-based aging and increased failure rates, the overall CDF for the simplified AdvSMR design was orders of magnitude smaller than those generally accepted for currently operating reactors. This is likely because of the small number of key components used in the PRA modeling as well as the use of passive safety features in AdvSMRs (resulting in significantly lower risk levels when considering active components). However, the CDF value (over time) in the examples investigated grows beyond the CDF generally accepted for currently operating reactors. This is a likely consequence of potentially inflated rates of growth for the probabilities of failure of the components; as realistic data on component failure rates from aging become available and additional AdvSMR design details are included in the PRA models, the time rate of change of the CDF can be better characterized. 
Importance analysis of the results showed that traditional measures of importance, such as risk achievement worth, appear to be less useful when applied to a model where failure rates and the calculated CDF change over time. For example, we noted one component failure to produce a high risk reduction worth value for exactly the years in which the total CDF was very low, so it was unclear how important this component failure was to risk compared with components with lower importance values in years when the CDF was very high. As a consequence, we postulate a new importance measure that includes consideration of the relative importance of the event to the total CDF as well as the value of total CDF itself. This proposed importance measure appears to improve the ability to distinguish between riskimportance of components under time-varying failure probabilities.

The results to date overall indicate the potential for using the ERM methodology for decisions on optimization of O\&M practices.

In addition, we conducted a study on the state of ECA for AdvSMRs, to identify technologies that may be leveraged to gather experimental data for use in evaluating the ERM framework. This study indicated that, while several ECA techniques exist for components used in current plants (which may be leveraged for similar components planned for AdvSMRs), techniques are as yet unproven for components (such as electromagnetic pumps) that are specifically designed for use in advanced reactors or AdvSMRs.

Ongoing work in developing the ERM will focus on (1) methods to directly incorporate equipment condition assessment for key components in the risk monitor; (2) identification of economic and other risk measures, in addition to the traditional safety measures; (3) developing PRA models that account for changing load and demand conditions (possibly resulting in changing success criteria); and (4) incorporation and integration of uncertainty related to probability of failure and equipment condition monitoring. 


\section{Acknowledgments}

The work described in this report was sponsored by the Small Modular Reactor Research and Development Program of the U.S. Department of Energy Office of Nuclear Energy. The authors gratefully acknowledge Ms. Kay Hass for her invaluable assistance in the technical editing and formatting

of this report. The authors also thank the technical peer reviewers for their feedback and assistance in improving this report. 



\section{Acronyms}

4S

AC

ACS

AdvSMR

CDF

DC

ECA

EF

EM

EPRI

ERM

FFTF

GIF

HRA

I\&C

ICHMI

LFR

LWR

MOV

NPP

NRC

O\&M

$\mathrm{Pb}$

$\mathrm{Pb}-\mathrm{Bi}$

PHM

POF

PRA

PRISM

PSA

RCP

RVACS

SMR

SSCs

TWR super-safe, small and simple (reactor)

alternating current

auxiliary cooling system

advanced small modular reactor

core damage frequency

direct current

equipment condition assessment

error factor

electromagnetic

Electric Power Research Institute

enhanced risk monitor

Fast Flux Test Facility

Generation IV International Forum

human reliability analysis

instrumentation and control

instrumentation, control, and human-machine interface

lead (or lead-bismuth) cooled fast reactors

light-water reactor

motor operated valve

nuclear power plant

U.S. Nuclear Regulatory Commission

operation and maintenance

lead

lead/bismuth eutectic

prognostics and health management

probability of failure

probabilistic risk assessment

Power Reactor Innovative Small Module

probabilistic safety assessment

reactor coolant pump

reactor vessel auxiliary cooling system

small modular reactor

systems, structures, and components

traveling wave reactor 



\section{Contents}

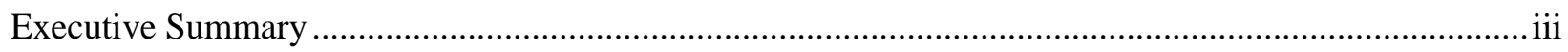

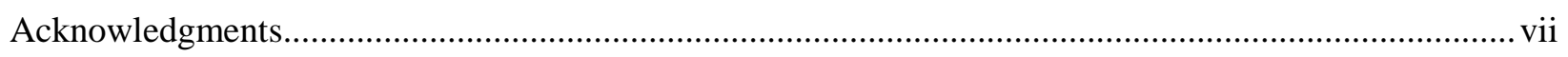

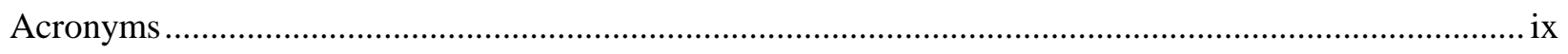

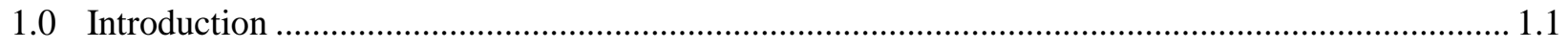

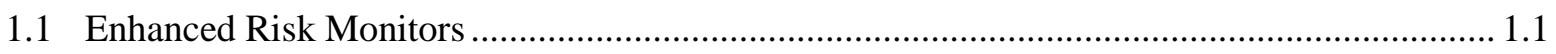

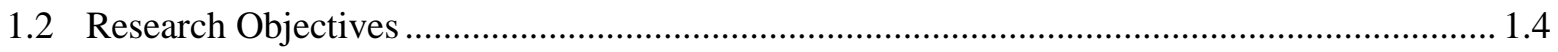

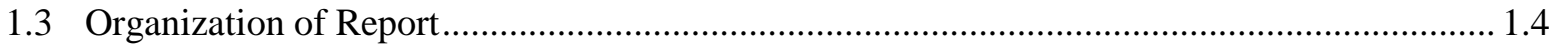

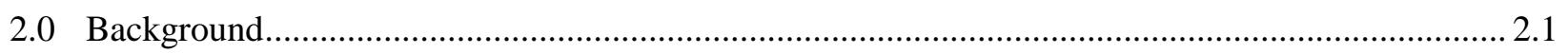

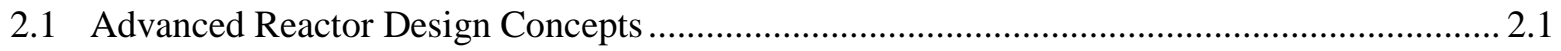

2.2 AdvSMR Operating Characteristics and ECA ................................................................... 2.1

2.2.1 Need for Monitoring Active Components in Advanced Reactors................................. 2.2

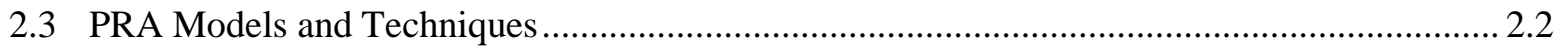

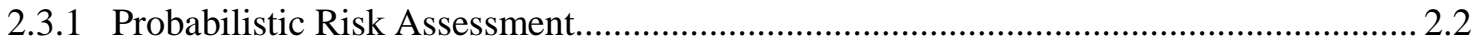

2.4 Technical Assumptions for ERM Methodology Development in AdvSMRs ......................... 2.6

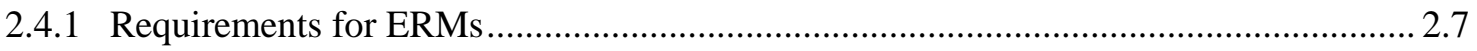

2.4.2 Simplified-model AdvSMR Design ........................................................................ 2.7

2.4.3 Key Components in the Simplified-model AdvSMR Design ..................................... 2.8

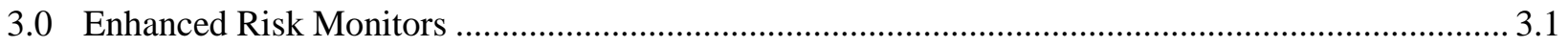

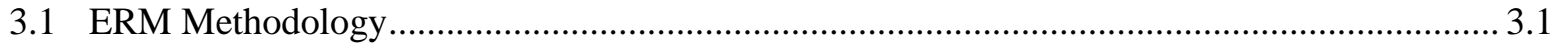

3.2 Equipment Condition Assessment ............................................................................ 3.3

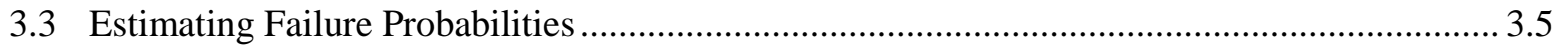

3.4 Initial Assessment of Proposed ERM Methodology .............................................................. 3.6

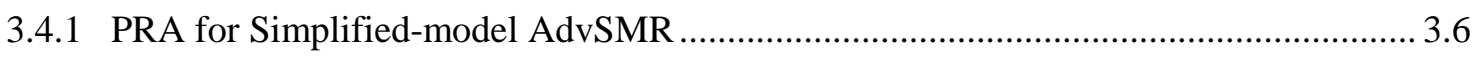

3.4.2 Initial Results for ERM Assessment …...................................................................... 3.10

3.4.3 Importance Analysis from ERM Results.................................................................... 3.13

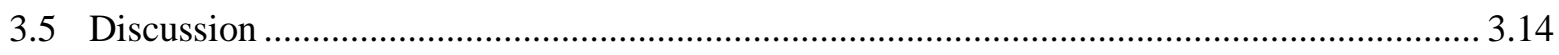

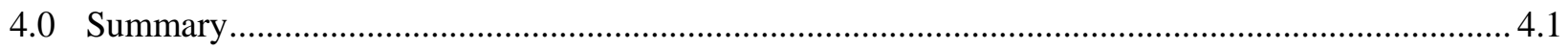

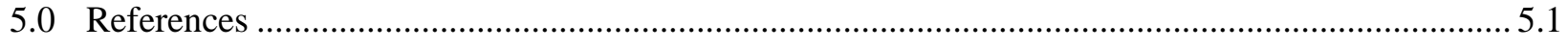

Appendix A - Sodium Fast Reactors Overview ............................................................................ A.1

Appendix B - Lead- (or Lead-Bismuth-) Cooled Fast Reactors Overview .................................................1 


\section{Figures}

1.1 Considerations and Steps to Achieving an Enhanced Risk Monitor............................................. 1.3

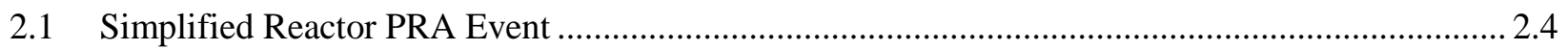

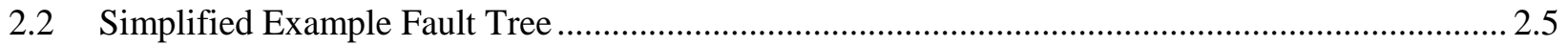

2.3 One-Line Diagram of Simplified-model AdvSMR...................................................................... 2.8

3.1 Generalized Component Failure Rate "Bathtub” Curve ................................................................ 3.1

3.2 Cutset \#1A CDF over Time Based on Time-Varying Event and Failure Probabilities ................. 3.11

3.3 Total CDF over Time Based on Time-Varying Event and Failure Probabilities.......................... 3.12

3.4 Variability in CDF from Variability in the Mean Failure Rate of One Component ..................... 3.13

3.5 Results of Postulated Importance Analysis................................................................................... 3.14

\section{Tables}

3.1 Example Equipment Condition Assessment Methods for Selected Active Components in

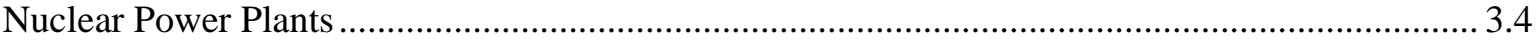

3.2 Assumed Dominant Cutsets for Example AdvSMR Power Block ................................................ 3.7

3.3 Initiating Event Frequencies and Component/System Failure Rates used in the Model ............... 3.10 


\subsection{Introduction}

Small modular reactors (SMRs) generally include reactors with electric output of 350 MWe or less (this cutoff varies somewhat but is substantially less than full-size plant output of 700 MWe or more). Advanced SMRs (AdvSMRs) refer to a specific class of SMRs and are based on modularization of advanced reactor concepts. AdvSMRs may provide a longer-term alternative to traditional light-water reactors (LWRs) and SMRs based on integral pressurized water reactor concepts currently being considered.

Enhancing affordability of AdvSMRs will be critical to ensuring wider deployment. AdvSMRs suffer from loss of economies of scale inherent in small reactors when compared to large ( greater than 600 MWe output) reactors. Some of this loss can be recovered through reduced capital costs through smaller size, fewer components, modular fabrication processes, and the opportunity for modular construction. However, the controllable day-to-day costs of AdvSMRs will be dominated by operation and maintenance $(\mathrm{O} \& \mathrm{M})$ costs.

Technologies that help characterize real-time risk are important for controlling O\&M costs through:

- Maximizing generation by assessing the potential impact of taking key components offline for testing or maintenance,

- Supporting reduced O\&M staff by aiding in optimization of O\&M planning (specifically by assessing the contribution of individual components to changes in risk and using this information for scheduling maintenance activities),

- Enabling real-time decisions on stress-relief for risk-significant equipment susceptible to degradation and damage, and

- Supporting potential remote siting by providing early warning of potential increases in plant risk.

Risk monitors are used in current nuclear power plants to provide a point-in-time estimate of the system risk given the current plant configuration (e.g., equipment availability, operational regime, and environmental conditions). However, current risk monitors are unable to support the capability requirements listed above as they do not take into account plant-specific normal, abnormal, and deteriorating states of active components and systems.

This report documents research results that are a step towards enhancing risk monitors that, if integrated with supervisory plant control systems, can provide the capability requirements listed and meet the goals of controlling O\&M costs.

\subsection{Enhanced Risk Monitors}

A fundamental challenge with unit-specific AdvSMR risk characterization is the potential for changing plant conditions as new operating regimes (including potential load-following and peak-demand power generation) and diverse missions (both electrical generation and process heat production) are being proposed. Current risk monitors generally are limited in their flexibility to address such changing conditions. In some cases, the introduction of modularity can introduce interconnections or dependencies between systems, structures, and components (SSCs) in reactor modules and generation blocks (multiple 
reactor modules connected to common balance-of-plant systems, such as the power blocks proposed for the Power Reactor Innovative Small Module [PRISM] reactor). Such interconnections can impact overall risk in ways that are very different from current operating nuclear power reactors.

Advanced plant configuration information, equipment condition information, and risk monitors are needed to support frequently changing plant configurations (Yoshikawa et al. 2011). To utilize these three, often disparate pieces of information in making real-time decisions on O\&M, approaches are needed to integrate these three elements in a manner that provides a measure of risk that is customized for each AdvSMR unit, and accounts for the specific operational history of the unit.

To achieve this integration, two separate technologies need to be integrated. These are:

- Risk monitors (that currently are based on probabilistic risk assessment (PRA) models)

- Technologies for determining, based on the operational history and current configuration of the unit and its components, the present state of the component (for instance, "likely to continue operating within specifications,” or "likely to fail soon with some probability,” etc.).

The second set of technologies are commonly referred to as diagnostic and prognostics technologies, in that they provide tools for the assessment of the current condition of SSC based on one or more measurements, and project (or predict) the operational condition at some defined time in the future based on the unit configuration and operational history.

Given this need to integrate these two sets of technologies, the general approach taken in this research is shown in Figure 1.1. The stages defined in this figure can be roughly related to identifying relevant SSC for which measurements are used to determine the current condition (equipment condition assessment (ECA)), and predict the condition (along with confidence levels in the prediction) at some point in the future (prognostics). The predicted condition, in the form of a probability of failure (POF) is integrated into risk monitors, resulting in an ERM. The ability to predict (or estimate for future times) the POF based on equipment condition assessments and incorporate these in ERM may also help compensate for a relative lack of knowledge about the long-term component behavior of some components that are being proposed for AdvSMRs.

Relevant SSCs are generally those that are considered risk-significant, although this list can change as the plant configurations and operational conditions change. It is important to ensure that in determining relevancy, such factors are considered. These key SSCs are then candidates for ECA.

The second stage is to identify measurements that can provide indicators of condition for each of the key SSCs. These may include process measurements (e.g., flow, temperature, and pressure), performance measurements (e.g., pump efficiency), or direct measurements (e.g., vibration and acoustic emissions). Challenges from the harsh environments in AdvSMRs may necessitate novel measurement methods, such as optical (Anheier et al. 2013) measurements of process parameters, or the use of sensors tolerant to these conditions (Daw et al. 2012). 


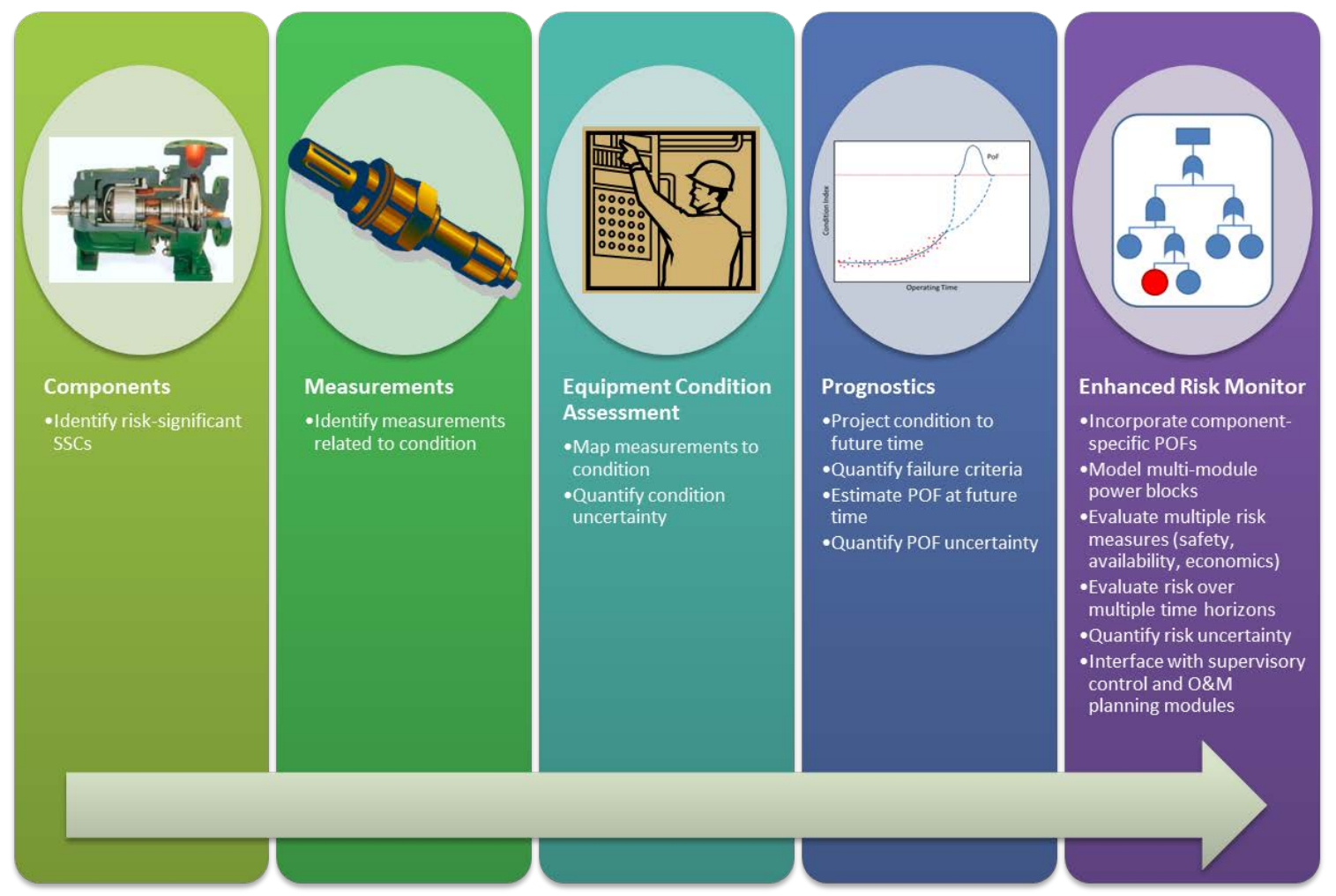

Figure 1.1. Considerations and Steps to Achieving an Enhanced Risk Monitor

These measurements are then applied to analysis algorithms to map the available measurements to condition indicators (shown in Figure 1.1 as ECA). ECA methods and instrumentation differ depending on whether the SSC is classified as active or passive. Passive components are generally those SSCs that do not move during normal functions while active SSCs do. Active components include pumps, generators, valves, control rod drives, etc., while passive components include structural elements such as the reactor vessel, heat exchanger piping, Class 1 piping, concrete containment, cables, etc.

The condition indicator is then projected to future times using appropriate prognostic algorithms (Coble et al. 2012; Meyer et al. 2013), and estimate POF distributions for each key SSC at some point in the future. These estimated POF distributions are used by the ERM to provide a more accurate assessment of the dynamic risk.

A previous study (Coble et al. 2013) documented requirements for ERMs in AdvSMR environments, and identified technical gaps towards the realization of ERMs for nuclear power reactors. This document reported on the progress towards addressing some of the technical gaps identified for ERM use with AdvSMRs. 


\subsection{Research Objectives}

This report describes research results from an initial methodology for ERMs by integrating real-time information about equipment condition and POF into risk monitors. This methodology is described using a model of a liquid-metal-cooled, modular AdvSMR design. Preliminary results of integrating timedependent component POF into a simplified risk monitor for the simplified-model AdvSMR design are described, and used to identify key areas for further development of the ERM framework.

The focus of the ERM methodology described in this report is on active components in AdvSMRs that are included in risk monitors.

\subsection{Organization of Report}

This technical report is organized as follows. Section 2 provides an overview of AdvSMR designs, health monitoring and ECA for nuclear power components, and PRA. Technical assumptions that were made during the development of the ERM methodology and its assessment are also documented. Section 3 describes ERM methodology and presents initial results, with Section 4 summarizing the findings and describing ongoing research. 


\subsection{Background}

The vast majority of nuclear power plant (NPP) operating experience involves light-water-cooled reactors and includes small LWRs. However, there is some experience with select advanced reactor concepts, which may be used to identify potential faults and failure modes for key components in AdvSMR concepts. Some of these issues are expected to be resolved in new AdvSMR designs (e.g., moisture intrusion through water-lubricated bearings may potentially be avoided by using sealed magnetic bearings); however, other issues may still be relevant. These issues are likely to drive inspection and maintenance requirements for AdvSMRs.

Generally, AdvSMR concepts are distinguished from other NPP concepts by three factors:

- Using non-light water coolants—coolants being proposed for AdvSMRs include liquid sodium, lead or lead-bismuth eutectic, helium, and molten salt.

- Deliberately small in size-typically, AdvSMR concepts are expected to have electrical output less than about 300 MWe.

- Potentially modular in configuration and operation.

Below, we briefly discuss advanced reactor concepts relevant to this research and provide background information on health monitoring, ECA, and PRA for nuclear power applications. This is followed by the technical assumptions that bound the research described in the rest of this document.

\subsection{Advanced Reactor Design Concepts}

Leading AdvSMR designs are based on the advanced reactor concepts identified by the Generation IV International Forum (GIF) (Abram and Ion 2008), and include liquid-metal-cooled, gas-cooled, molten-salt, and supercritical water reactor concepts. Of these, the greatest amount of operating experience comes from liquid-metal-cooled and gas-cooled reactors. Both of these advanced reactor concepts have also been used in AdvSMR designs, and are likely to be closer to moving through the design and deployment cycle than AdvSMR concepts based on other coolant materials.

The appendices of this report include summaries of the generic features of liquid-metal-cooled reactor concepts. Details of other advanced reactor concepts are available in the previous report in this series (Coble et al. 2013). Additional background on other advanced reactor concepts and operational experience are available in the report on prototypic prognostic techniques for AdvSMRs passive components (Meyer et al. 2013).

\subsection{AdvSMR Operating Characteristics and ECA}

The operating characteristics of proposed AdvSMR designs impose challenges to real-time ECA. Several AdvSMR concepts use pool-type or integral configurations or very compact arrangements, which reduces accessibility to key components. These designs are also expected to have fewer offline component testing and maintenance opportunities because of longer operating cycles between refueling.

Health monitoring would provide condition indicators for key equipment using online, in-situ sensors and measurements to support detection and identification of incipient failure and to reflect evolving 
degradation. This is particularly important for SSCs proposed for use in AdvSMR designs that differ significantly from those used in the operating fleet of LWRs—or even in LWR-based SMR designs), as operational characteristics for these SSCs may not be fully available.

In proposed AdvSMR designs, a number of active components may be identified. Determining whether available condition monitoring techniques may be applicable to these components is a necessary step to leveraging existing technologies to the fullest extent possible. Below, we briefly discuss the motivation for considering active components for ERM.

\subsubsection{Need for Monitoring Active Components in Advanced Reactors}

In spite of the likelihood of AdvSMRs relying on passive mechanisms to achieve safety goals, active components are expected to play an important role in plant operations and maintenance. First, a number of active components (e.g., coolant pumps, compressors, and circulators) will be needed for reliable operation of the AdvSMR system. Unexpected failures of one or more of these active components or systems (whether they are safety-related or not) are expensive to address as they may require unplanned shutdown of the reactor module. Additionally, some non-safety but potentially risk-significant systems require active components for initiation of passive features. For example, the PRISM auxiliary cooling system (ACS), which supports shutdown heat removal, is initiated by opening inlet and outlet louvers in the steam generator building to allow natural circulation and air-cooling of the steam generators and circulation of sodium in the intermediate loop (NRC 1994).

The greater reliance on passive mechanisms for safety goals may, paradoxically, increase the risk significance of the active components that are still used. This is because traditional risk measures such as core damage frequency (CDF) (see Section 2.3 for definition) for AdvSMRs could be several orders of magnitude lower than for currently operating nuclear power plants as a result of these passive features, and the fact that the POF for passive systems is generally low. Consequently, the relative risk importance of active systems can increase.

\subsection{PRA Models and Techniques}

Current risk monitors use PRA techniques that have been used in U.S. nuclear power plants to assess the risks associated with operation since the 1980s (Wu and Apostolakis 1992). PRA systematically combines event probability and POF for key components to determine the hazard probability for subsystems and the overall system (Kafka 2008). In general, PRA models use a static estimate for event probability and POF, typically based on historic observations and engineering judgment. More recently, time-based POF values have been used (Vesely and Wolford 1988; Arjas and Holmberg 1995); however, these are derived from operating experience and traditional reliability analysis and are usually not specific to the operating component.

\subsubsection{Probabilistic Risk Assessment}

In general, risk can be defined as the product of the frequency of an event and its consequence:

$$
\text { Risk }=\text { Frequency } \times \text { Consequence }
$$


where Consequence refers to undesirable outcomes (reactor core damage, release frequency of radionuclides, cancer deaths, etc.) and Frequency is the likelihood of the consequence per unit time. In the nuclear industry, risk is typically evaluated for events that have consequences related to public health and safety.

The assessment of risk with respect to NPPs is intended to achieve the following general objectives (Fulwood and Hall 1988):

- Identify initiating events and event sequences that might contribute significantly to risk;

- Provide realistic quantitative measures of the likelihood of the risk contributors;

- Provide a realistic evaluation of the potential consequences associated with hypothetical accidents; and

- Provide a reasonable risk-based framework for making decisions regarding nuclear plant design, operation, and siting.

PRA is a systematic safety analysis methodology that (Haasl et al. 1988; Apostolakis 2000) begins by identifying undesirable consequences (e.g., reactor unavailability, core damage, release of radioactivity) and initiating events that can lead to these consequences. This is followed by systematically identifying accident sequences [defined by event trees (Papazoglou 1998) and fault trees (Vesely et al. 1981)] through which the facility can move from the initiating event to the undesired consequence. The PRA model then calculates the probability of occurrence for each accident sequence and ranks the accident sequences according to probability of occurrence (or, alternatively, contribution to the undesirable event) to manage the major contributors to risk.

Three levels of PRA, designated by the type of risk being assessed, have been considered for NPPs (NRC 2012). Level 1 PRA estimates the frequency of accidents that cause core damage (commonly called core damage frequency); Level 2 PRA, the frequency of radioactive release from the NPP (assuming that the core is damaged); and Level 3, the consequences to the public and environment outside the NPP from Level 2 radioactive releases. The ultimate result of the PRA is the probability of each undesirable consequence (e.g., core damage, radioactive release) and a list of the major contributors to its occurrence.

A full PRA model consists primarily of event trees and fault tree models that, when solved, produce cutsets representing the combinations of failures that result in an accident sequence and define the likelihood of those failures (EPRI 2011). Fault trees and event trees define Boolean relationships among fault events that cause the top event to occur. Event trees define logic among fault trees in a way that accident sequences can be translated entirely into an equivalent set of Boolean equations. This logic can be reduced to an expression of cutsets. The list of cutsets for an accident sequence represents all combination failures leading to that accident sequence. The dominant cutsets represent the most important combinations along with the frequency or probability of those failures.

An event tree is a diagram that defines accident sequences. Each horizontal "pathway" running from left to right through an event tree defines an accident sequence beginning with an initiating event, followed by a series of top events (i.e., the systems and/or actions needed to mitigate the initiating event), and finishing at a particular plant end state (e.g., plant damage). Each branch point of the event tree 
represents a question asked about the status or condition of a system. Traditionally, the up branches indicate success while the down branches indicate failure. Figure 2.1 shows an example event tree.

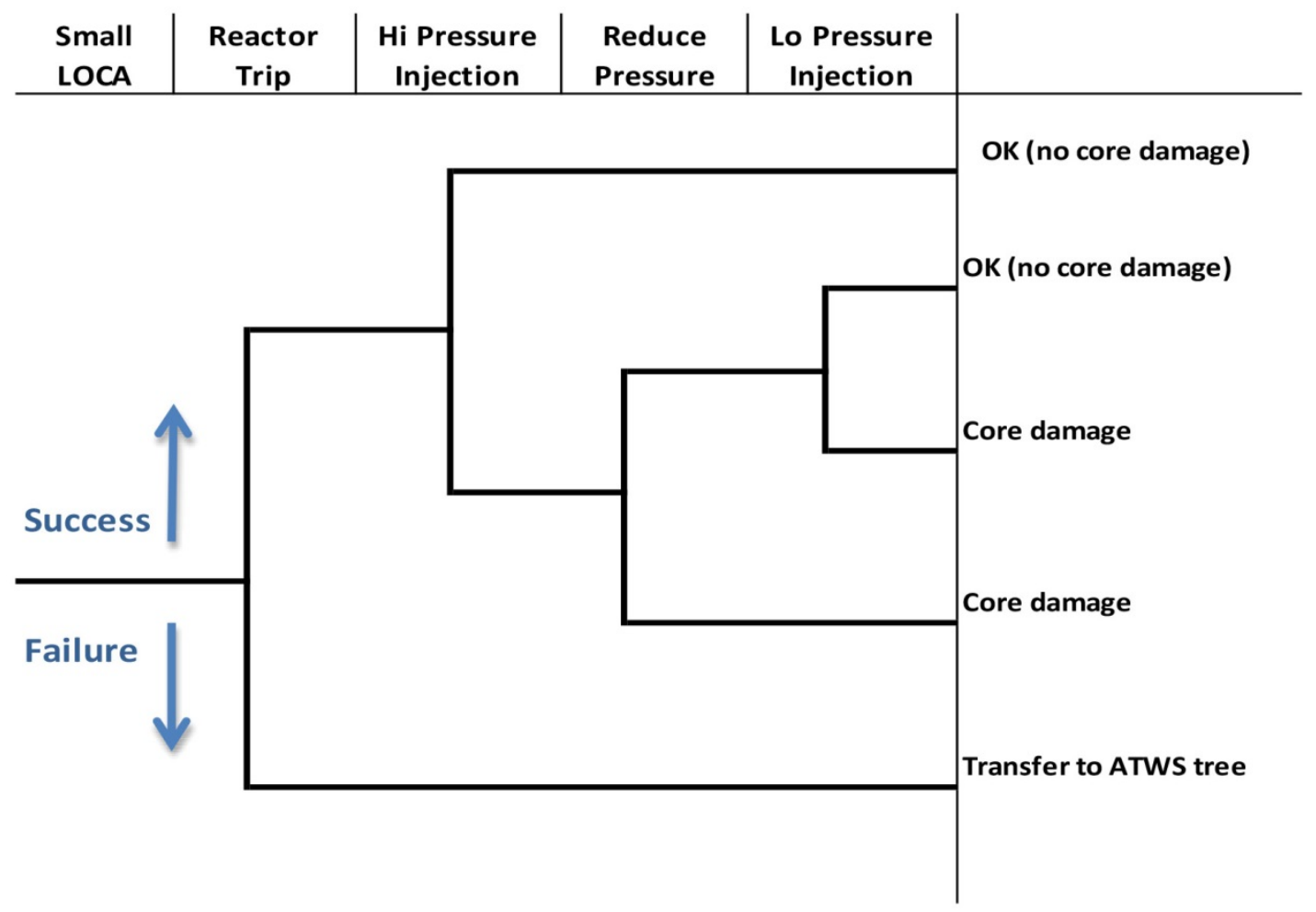

Figure 2.1. Simplified Reactor PRA Event (NRC Undated)

Fault trees are graphic models depicting the various fault combinations that will result in the occurrence of an undesired (i.e., top) event. A simple fault tree is presented in Figure 2.2. Fault tree analysis is an analytical technique, whereby an undesired state of the system is specified, and the system is analyzed in the context of its environment and operation to find all credible ways in which the undesired event can occur (Vesely et al. 1981).

Both passive and active components may be included in fault trees and event trees. Typical active component failures include: 1) failure to run, 2) failure to start, 3) failure to open or close or operate, and 4) unavailability because of test or maintenance. Typical passive component failures include: 1) rupture, 2) plugging, 3) failure to remain open or closed, and 4) cold or hot short of power or instrument cables.

Each failure event in the fault tree is called a basic event and has a component failure or human error probability associated with it. Component failures are typically demand- or time-related (e.g., valve fails to close on demand, or pump fails to run for 24 hours). Data for component failure rates and failure probabilities comes from generic sources, plant-specific sources, or a combination of the two (as when generic data is adjusted using plant-specific data by performing a Bayesian update). Aging-related failure data, if included, typically utilizes reliability models(Vesely and Wolford 1988; Smith et al. 2001). Human error probabilities are generally compiled using human reliability analysis (HRA) that is based on 
research done in NPP control rooms and simulators. HRA is an important part of PRA, and considers such performance-shaping factors as stress level, crew resources, cues, and timing.

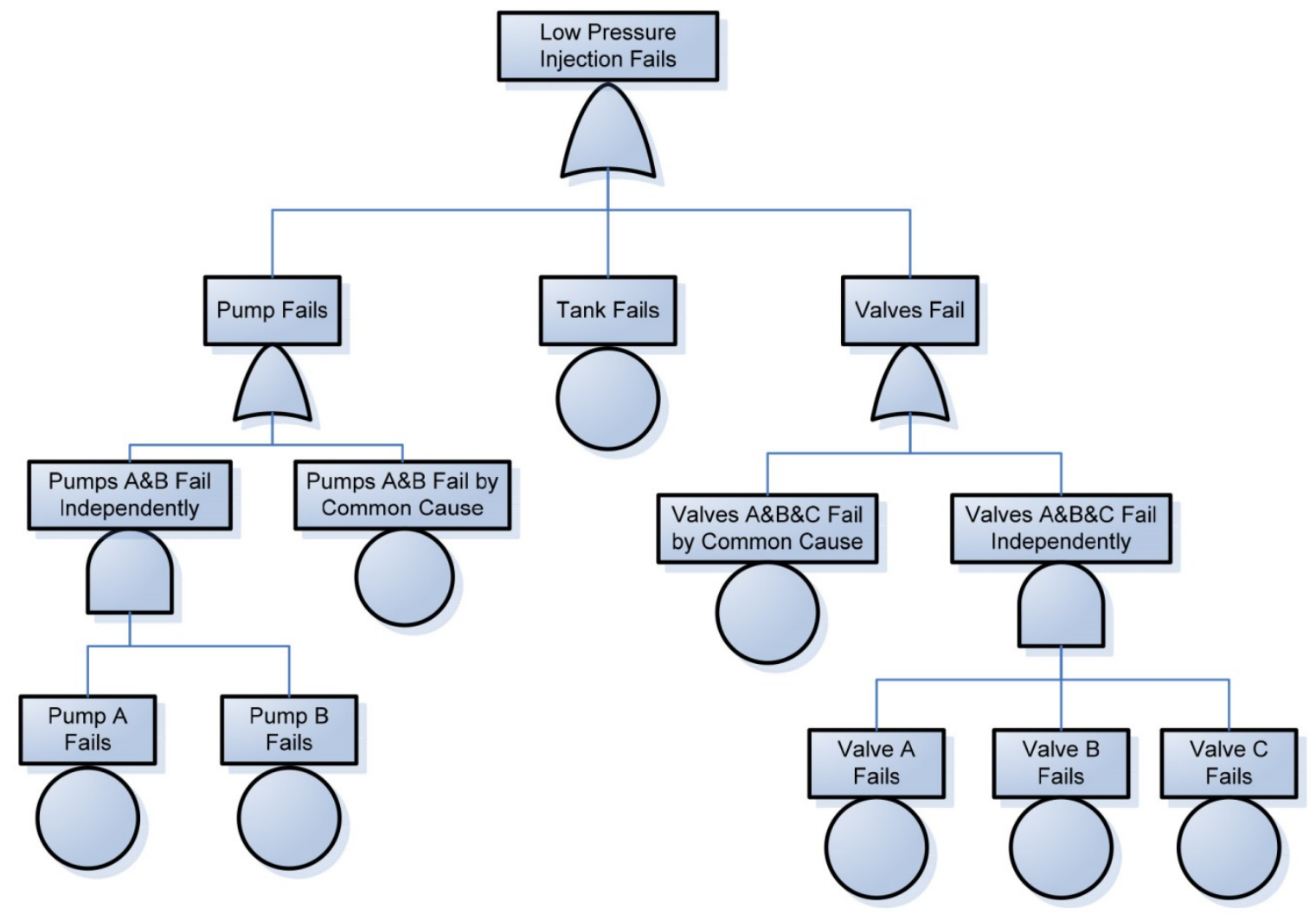

Figure 2.2. Simplified Example Fault Tree (NRC Undated)

Importance analysis is typically performed on the results of a PRA and provides a quantitative perspective on risk and sensitivity of risk to changes in input values (Vesely et al. 1983). Three commonly encountered importance analyses are determination of risk achievement worth (RAW), risk reduction worth (RRW), and Fussell-Vesely (F-V). These analyses produce different kinds of measures of basic or initiating event importance, such as determining the ratio of the total CDF produced when a particular basic event is set to either one or zero to the baseline CDF produced when the basic or initiating event is set to its nominal value. For instance, RRW analysis uses the ratio of the baseline risk to the reduced risk calculated by assuming a component is completely reliable (i.e., no failures) (Vesely et al. 1983). Importance measures are valuable in sorting out the most important component failure modes.

Uncertainty in PRA modeling arises from a number of sources that are typically divided into aleatory variability and epistemic uncertainty (EPRI 2011). Aleatory variability is related to the statistical confidence we have in failure probability data, while epistemic uncertainty is related to the uncertainty in the accident sequences used to develop the PRA model. Epistemic uncertainty is dealt with by developing event and fault trees as complete as possible, identifying keys sources of uncertainty, and performing sensitivity analyses. The aleatory variability is addressed explicitly by propagation of 
parametric data uncertainty for initiating basic event data. Uncertainty analysis is performed through a sampling strategy (e.g., Monte Carlo sampling) over some number of observations.

As PRA models are integrated into plant management, they have become living models that reflect the as-modified and as-operated plant configuration and are able to estimate the changing likelihood of undesired events. Risk monitors extend the PRA framework by incorporating the actual and dynamic plant configuration (e.g., equipment availability, operating regimes, and environmental conditions) into

the risk assessment, although failure data on equipment is based on operational experience and reliability analysis, and unit-specific failure information is generally not used.

\subsection{Technical Assumptions for ERM Methodology Development in AdvSMRs}

Several key assumptions are made in the development of the preliminary methodology for ERM that integrates time-dependent failure probabilities that are specific to the unit and the component condition. These are:

- The key aspects of the ERM methodology may be developed and initially assessed using a simplified model of an AdvSMR. In particular, we assume that the simplified model is of a liquid-metal-cooled AdvSMR.

- The focus of the ERM methodology described in this report is on active components in AdvSMRs that are included in risk monitors.

- Effective ECA techniques are assumed to be available for key active components and systems, including identification of the measurements necessary to perform ECA.

- Sensors for making the measurements needed for effective ECA are assumed to exist. These include measurements that are sensitive to component condition (such as vibration or current/voltage) as well as measurements of the operational environment (stressors). Ongoing research into sensors (such as that documented in Anheier et al. (2013) and Daw et al. (2012)) will be leveraged where possible.

- We assume that existing prognostic algorithms will provide accurate extrapolation of equipment condition through future operation, as well as confidence bounds on the extrapolation; new approaches to prognosis are not a focus of this research. Investigations into prognostics health management (PHM) including risk assessment of passive components are covered separately as summarized in the report on prototypic prognostic techniques for AdvSMRs passive components (Meyer et al. 2013). Developments in this area, with appropriate modifications to address active components, will be leveraged as needed.

- For the initial assessment of the ERM methodology, POF estimates at future time instants for the components identified in the simplified AdvSMR design are assumed to be available; however, the specific ECA technique and prognostic algorithm are not defined at this stage.

- Cross-coupling of components and systems in connected reactor modules is assumed to be captured in well-developed PRA models. However, the initial ERM methodology does not explicitly account for these interdependencies. 
The development of the ERM methodology was also driven by the functional requirements for ERMs. These are briefly summarized next. However, the preliminary methodology addresses only a sub-set of these requirements, with additional development necessary to address the other requirements.

\subsubsection{Requirements for ERMs}

ERM functional requirements are numerous, and are a result of the need to integrate unit-specific estimates of the POF, by using real-time or near-real-time condition knowledge of the equipment, into operational risk monitors, as well as features of AdvSMRs. The functional requirements are described in detail in Coble et al. (2013) and include the ability to:

- integrate online, real-time ECA

- apply to multiple, interconnected modules and generation blocks

- evaluate risk over multiple time horizons

- apply condition-specific fault trees, event trees, and success criteria

- support reconfigurable balance-of-plant and fluctuating generation demands

- evaluate multiple risk measures

- meet runtime requirements for control and O\&M planning.

\subsubsection{Simplified-model AdvSMR Design}

A simplified-model AdvSMR (power block) design is used in the development of the PRA model used for the research that supported the development of a framework for ERMs. This simplified model is shown in Figure 2.3. This hypothetical design is intended to be prototypical and resembles proposed liquid metal-cooled SMR designs. The example design is defined to provide a simple level of abstraction but contains enough resolution and specific design elements to inform the development of a PRA model that, when quantified, produces a cogent set of results.

The simplified-model AdvSMR design in Figure 2.3 is a small, modular, pool-type, liquid-metalcooled reactor assumed to be producing 200 to $500 \mathrm{MWt}^{(\mathrm{a})}$ of power. The plant design consists of an unspecified number of identical power blocks, with each power block comprised of two reactor modules. Each module is connected to its own intermediate heat exchange system and steam generator. The secondary side (i.e., steam side) equipment is located in a different building and connects two modules to form a power block. A power block feeds a single variable capacity turbine generator. (Note: While a greater number of reactor modules in a power block are possible, two modules provide enough complexity to develop and demonstrate a methodology for ERM.)

(a) The electrical output of a reactor depends on the efficiency of the power conversion process. 


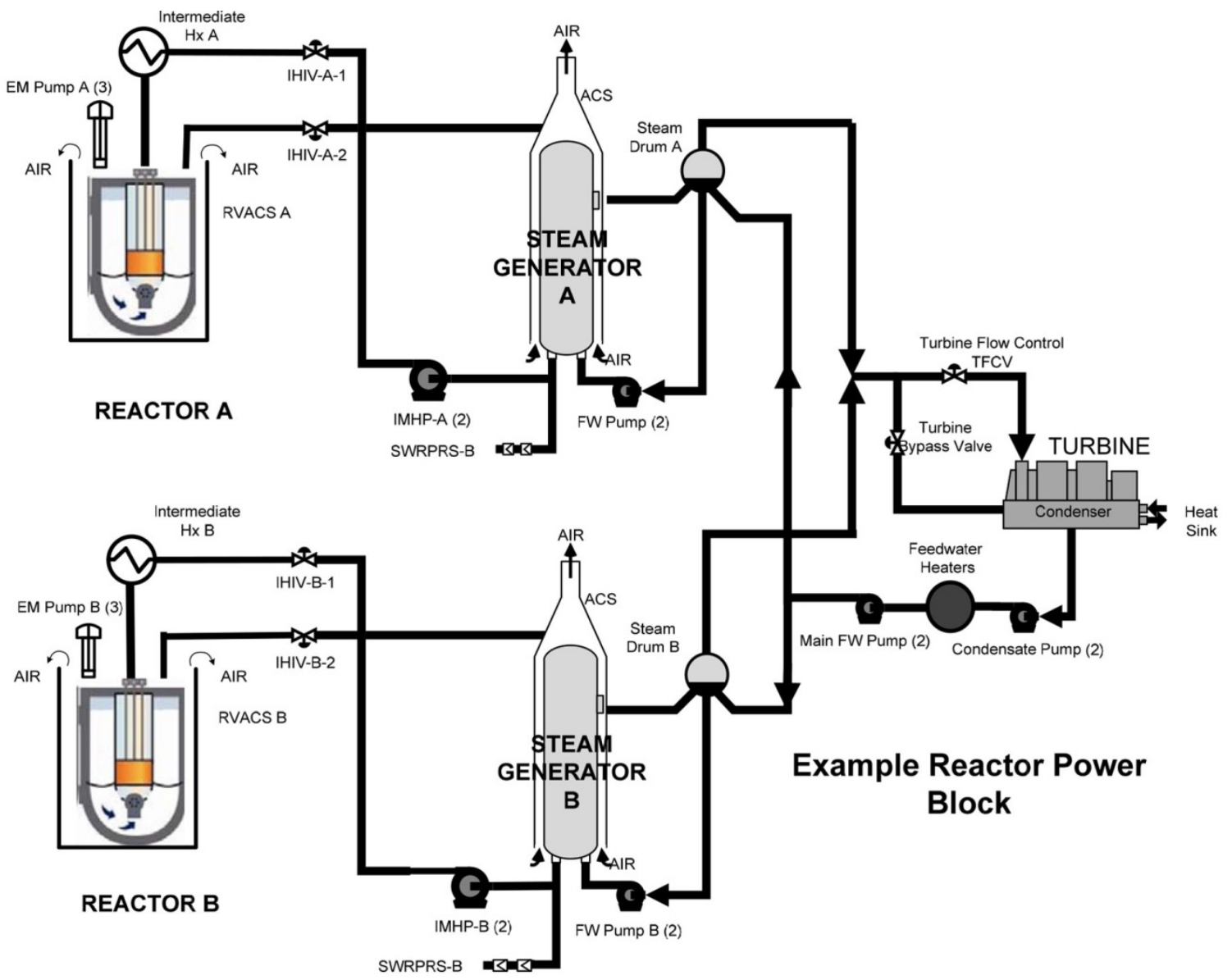

Figure 2.3. One-Line Diagram of Simplified-model AdvSMR

\subsubsection{Key Components in the Simplified-model AdvSMR Design}

The components defined for modeling in the example reactor power block are:

- Electromagnetic pumps (3 per reactor module)

- Reactor vessel auxiliary cooling system (RVACS) (1 per reactor module)

- Intermediate heat exchangers (1 per reactor module)

- Intermediate loop isolation valves (2 per reactor module)

- Intermediate loop pumps (2 per reactor module)

- Steam generators (1 per reactor module)

- Liquid-metal water-reaction pressure relief system (1 per reactor module)

- Steam drum (1 per reactor module)

- Feedwater pumps (2 per reactor module)

- Passive steam generator cooling system (1 per reactor module) 
- Turbine generator (1 per power block)

- Turbine bypass valve (1 per power block)

- Turbine flow control valve (1 per power block)

- Main feedwater pumps (2 per power block)

- Main feedwater heater (1 per power block)

- Main condensate pumps (2 per power block)

- Emergency diesel generator (1 per power block)

The primary features of the simplified design are the primary cooling loop, intermediate cooling loop, secondary system including the steam generators, and residual heat removal systems consisting of a passive RVACS and passive steam generator cooling system.

The primary loop is contained entirely within the reactor vessel. Liquid metal is pumped by electromagnetic pumps up through the reactor core and out through the top. Flow is then forced back down through the space (annulus) between the outer wall and reactor core past two intermediate heat exchangers. The electromagnetic pumps are suspended into the reactor pool from above. Because electromagnetic pumps have no moving parts and therefore there is no associated "flywheel effect," a synchronous coast-down function is designed into pumps to provide coast-down upon loss of power.

The intermediate loop transfers heat to the secondary system via two steam generators. The primary components of this system are the steam generator, the intermediate cooling pumps, and the intermediate loop isolation vales. The intermediate cooling pumps force flow of heated liquid metal from the intermediate heat exchangers to the steam generators during both normal and upset conditions. The isolation valves close to isolate the reactor from a pressure increase resulting from the liquid-metal-water interaction that would occur in the event of a steam generator tube rupture event. The signal to close these isolation valves is based on a passive liquid-metal-water pressure-relief system connected directly to the steam generators.

The secondary system consists of a steam generator and a steam drum for each reactor module connected to a single turbine generator. The secondary system delivers steam from the steam generators to the inlet of the turbine. Turbine steam exhaust flows through the condensers and then to main condensers and feedwater pumps back to the reactor module steam drums where it can be pumped by the reactor module feedwater to the steam generators. The turbine bypass valves allow steam to flow past the turbine and directly into the condenser when required. This allows a means of residual heat removal from the reactor modules during reactor shutdown and startup, and provides a flow path that will be needed in case of load rejection and some event that trips the turbine. Each steam generator has a liquid-metalwater reaction pressure-relief system that relieves pressure in the event of a generator tube rupture. This is a passive system and provides a path for the increased steam pressure that would occur from liquidmetal-water reaction.

The residual heat removal system consists of RVACS and the passive steam generator cooling system. The passive steam generator cooling system removes heat by air circulation past the steam generators. This airflow is initiated by remote manual opening of louvers at the inlet and outlet of the shroud around the steam generators. In this mode, heat is removed by natural convection to the air. This 
system can operate with forces or natural circulation of intermediate cooling loop sodium. If operators are unsuccessful at opening louvers to initiate convective cooling or if the intermediate cooling flow or inventory is lost, then a residual heat can by removed by natural air circulation around the containment vessel that surrounds the reactor vessel via the RVACS. Heat will be transferred from the reactor vessel to the containment vessel by radiative heat transfer and then to the air around the containment vessel and ultimately the atmosphere via convective heat transfer. A key design feature of RVACS is that no components or operator actions are required to initiate RVACS, because it is continually operating during normal power operation and is designed to be able to accommodate residual heat transfer after reactor shutdown. 


\subsection{Enhanced Risk Monitors}

This section describes an initial methodology for enhanced risk monitors that integrate equipment condition assessment for dynamic characterization of system risk. The proposed methodology is applied to a risk monitor derived from the simplified AdvSMR design (Section 2.4.2) and the results are described.

ECA is a requirement for ERM, and as discussed in Section 2.4, techniques for ECA are assumed to exist for the selected components of an AdvSMR. Thus, the state-of-the-art for ECA constrains the ability to deploy the ERM methodology and a better understanding of the state-of-the-art for ECA is needed before research needs for ECA of AdvSMR components may be defined.

This section begins by describing the ERM methodology, including the general approach to integrating ECA/prognostics results with risk monitors. An overview is then provided of the state of ECA techniques for typical active components expected in a liquid-metal AdvSMR. This is followed by an assessment of the ERM methodology as applied to the simplified AdvSMR design described in Section 2.4.2.

\subsection{ERM Methodology}

As described earlier, ERMs require integration of two sets of technologies—risk monitors and ECA/prognostics. In this section, we describe an approach to accomplishing this integration.

Time-independence of component failures is assumed in traditional PRA modeling, and PRA component failure rates are typically assumed to be static over the life of the component. Changes (i.e., degradation) in the failure rate of a component that might be expected to normally occur over the component life are not explicitly represented. However, experience has shown that aging of components generally results in time-dependent failure rates (Vesely and Wolford 1988). In reliability engineering, the failure probability is often defined to be a "bathtub" curve similar to that shown in Figure 3.1 (failure probability expressed as $\lambda(\mathrm{t})$ in the figure).

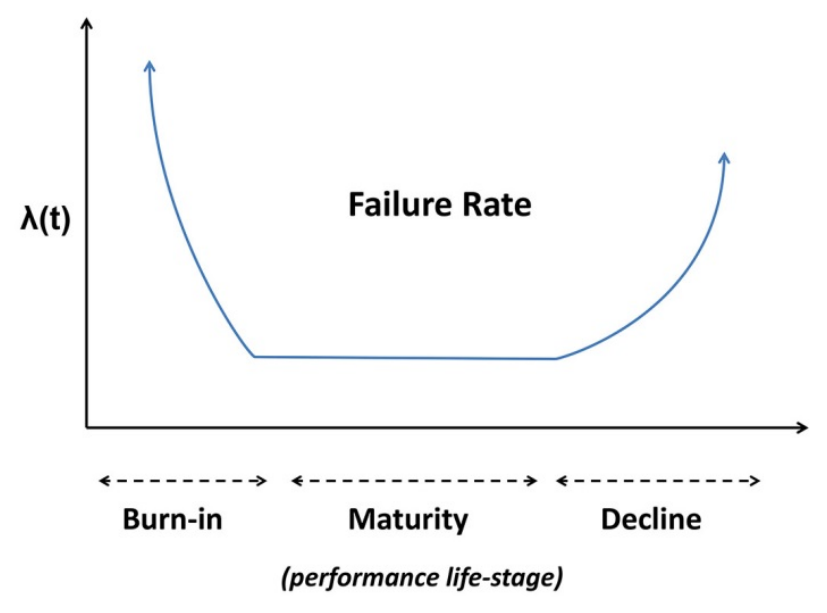

Figure 3.1. Generalized Component Failure Rate "Bathtub” Curve 
The ERM methodology that is being developed removes the fundamental assumption of static failure rates in risk monitors by integrating component-specific time-dependent failure probabilities that are calculated based on the current condition of the equipment.

We begin by defining PRA models that include all relevant components, as well as interdependencies between different modules of AdvSMRs. Component relevancy is determined by performing a failuremodes-and-effects analysis (FMEA) that takes into account all potential operating conditions (for example, full power steady-state operation, load-following, and reactor run-back). This information is used in the development of fault trees and event trees of the PRA model. These are solved to identify the cutsets that contribute most to risk.

For each of the relevant components, ECA methods are deployed to monitor the condition of the equipment and the surrounding environment. This information is used by a prognostic algorithm to predict the probability of failure at a specified future time given the current condition of the component. As additional measurements become available (for instance at successive time instants), the predictions may be improved by making use of updated condition information.

The component-specific time-dependent failure information (POF and confidence bounds) is then integrated into the PRA model and the PRA model is solved to provide a time-dependent risk measure (such as the change in CDF with time).

Existing importance measures are based on the use of static failure rates, and may be less useful when applied to a model where failure rates and the calculated CDF change over time. A primary reason for this is the manner in which traditional importance analysis is generally performed; that is, through the use of ratios. This may be understood using a simple example. RAW is expressed as the ratio of the risk calculated with the element (e.g., basic event) always failed or unavailable to the baseline risk (Vesely et al. 1983). In the case where the baseline CDF changes with time (as does the POF), assuming a component is fully available does not change the time-dependency of the CDF (because other components are still assumed to have time-dependent POF values), although the values may be different from the baseline case. Taking ratios under these circumstances may result in large excursions in the RRW (because of division by small numbers) that mask important details. Consequently, a failure event with a high-importance value at a given point in time might not be as important as a lower importance value at another point in time.

A more useful measure of importance must include consideration of the relative importance of the event to the total CDF as well as the value of total CDF itself. As a starting point, we postulate a new importance measure in which the component failure of interest is set to a value of 1.0 (i.e., the component is assumed unavailable), the total CDF recalculated, and ratio of the CDF to a target CDF is calculated. This approach examines the relative increase in risk over the time-horizon of interest (when compared to a static or time-independent risk profile) due to the unavailability of a component. Other options for importance analysis may also be of relevance and will be investigated in the future. 


\subsection{Equipment Condition Assessment}

ECA has been an active area of research for several decades. Several reviews of ECA research and developments are available [e.g., Schwabacher (2005), Schwabacher and Goebel (2007), and Hines et al. (2008)]. Kothamasu et al. (2006) reviews approaches to system health monitoring and prognostics, including specific applications to vibration monitoring of rotating equipment, gearboxes, and bearings. The Electric Power Research Institute (EPRI) extended their existing Preventative Maintenance Basis Database to include an assessment of the applicability of prognostics to various systems and components in power generating systems (EPRI 2009); this assessment includes a list of potential measurements for assessing degradation. A recent review by Coble et al. (2012) summarizes the state of the art in equipment monitoring, fault detection, diagnostics, and prognostics for nuclear power plant components and systems. ECA systems, including predictive maintenance, prognostics and health management (PHM), and health monitoring, typically detect and diagnose faults and estimate the remaining useful life of a system or component, but this approach can be modified and extended to instead provide the instantaneous POF distribution or the POF over some specified time window.

For the active components in nuclear power plants, PHM systems can capitalize on the information already collected by the plant instrumentation and control (I\&C) system, such as temperature, flow, and pressure. Pump health may be estimated using discharge pressure and flow; valve operation could be monitored through the changes in flow as the valve position setpoint is changed. For some active components, additional measurements may be useful or necessary for more robust and accurate prognostic models. Pumps and motors can be monitored through vibration measurements (e.g., Jarrell et al. 2004); in fact, reactor coolant pumps and casing are commonly monitored through the reactor coolant pump vibration monitoring system (Koo and Kim 2000). However, these systems do not currently support automated, online analysis of the vibration data to detect and diagnose abnormal conditions. Motors, such as those used for motor-operated valves (MOVs), can be monitored through multiple features, including input current and voltage, active power, motor position measures, and applied forces. Many of these additional measurements may be obtained autonomously, online, and unobtrusively.

While AdvSMRs will likely employ some advanced component designs (e.g., magnetic pumps and bearings), work on conventional component designs forms a basis for developing similar monitoring capabilities for these new designs. Based on the information summarized in Section 2.4.3, components of particular risk-importance include electromagnetic pumps, valves (both air-operated and motor-operated) and other pumps, and control rod drive systems. Table 3.1 lists potential ECA approaches for these types of components. In some cases (such as coolant pumps in liquid-metal), the literature on ECA approaches appears to be sparse. In these cases, techniques that may be applicable (based on similar classes of components, or on physics-based analysis of the component) are listed. In addition, a number of passive components are described that are safety significant-these are assumed to be inspected and assessed frequently and, with the exception of the RVACS (Razzaque et al. 1989), condition assessment methods for these components are not included within the following discussion. In general, from the available literature, it appears that, for several likely active components in AdvSMRs, available ECA techniques may be leveraged. 
Table 3.1. Example Equipment Condition Assessment Methods for Selected Active Components in Nuclear Power Plants

\begin{tabular}{|c|c|c|c|}
\hline $\begin{array}{l}\text { Component } \\
\text { Type }\end{array}$ & $\begin{array}{c}\text { Condition Assessment } \\
\text { Approach }\end{array}$ & Measurements & Selected References \\
\hline \multirow{3}{*}{$\begin{array}{l}\text { Pumps } \\
\text { (coolant, } \\
\text { feedwater and } \\
\text { condensate) }\end{array}$} & Process monitoring & $\begin{array}{l}\text { Speed, vibration, power, discharge } \\
\text { pressure }\end{array}$ & $\begin{array}{l}\text { Gross et al. (1993); Cho and Hong } \\
\text { (1998); Stegemann et al. (1998) }\end{array}$ \\
\hline & Stressor-based assessment & & $\begin{array}{l}\text { Vitkovskii et al. (1988); Jarrell et al. } \\
\text { (2004) }\end{array}$ \\
\hline & Frequency analysis & Vibration & $\begin{array}{l}\text { Koo and Kim (2000); Jung and Seong } \\
\text { (2006); Thirumalai et al. (2010); Sharp } \\
\text { (2012) }\end{array}$ \\
\hline \multirow{6}{*}{$\begin{array}{l}\text { Valves (motor } \\
\text { operated and air } \\
\text { operated) }\end{array}$} & Nondestructive evaluation & Acoustic emission & Nakamura and Terada (1985) \\
\hline & & Ultrasonic inspection & McShane and Ulerich (1992) \\
\hline & Position and process & $\begin{array}{l}\text { Motor current and valve stem strain } \\
\text { and position }\end{array}$ & $\begin{array}{l}\text { Arcella et al. (1994); Karpenko and } \\
\text { Sepehri (2002); Gomes et al. (2010) }\end{array}$ \\
\hline & Mechanical & Position; torque & $\begin{array}{l}\text { Chai et al. (1994); Kang et al. (2006); } \\
\text { Daigle and Goebel (2010) }\end{array}$ \\
\hline & $\begin{array}{l}\text { Electrical analysis (motor- } \\
\text { operated valves only) }\end{array}$ & Voltage and current & $\begin{array}{l}\text { Kueck et al. (1992); Mukhopadhyay } \\
\text { and Chaudhuri (1995); Kang et al. } \\
\text { (2006); Granjon (2011) }\end{array}$ \\
\hline & & Stator variables & Chai et al. (1994) \\
\hline \multirow{4}{*}{ Motors } & Physical quantities & Vibration, temperature & $\begin{array}{l}\text { Upadhyaya et al. (1994); Seker et al. } \\
\text { (2003); Maruthi and Vittal (2005); } \\
\text { Korkua et al. (2010) }\end{array}$ \\
\hline & $\begin{array}{l}\text { Motor current signature } \\
\text { analysis }\end{array}$ & Motor current & $\begin{array}{l}\text { Thomson and Fenger (2001); Seker et } \\
\text { al. (2003); Eren et al. (2005) }\end{array}$ \\
\hline & & Current, voltage, motor speed & Trutt et al. (2002) \\
\hline & Digital rotor telemetry & & Maughan and Reschovsky (2010) \\
\hline \multirow{4}{*}{$\begin{array}{l}\text { Control Rod } \\
\text { Drive }\end{array}$} & & Current signal and noise analysis & Gunther and Sullivan (1991b) \\
\hline & & $\begin{array}{l}\text { Circuit continuity and insulation } \\
\text { integrity in coils }\end{array}$ & Gunther and Sullivan (1991b) \\
\hline & & Neutron noise analysis & Pázsit and Analytis (1980) \\
\hline & & Control rod position & Wallace et al. (2010) \\
\hline \multirow{3}{*}{$\begin{array}{l}\text { Turbine- } \\
\text { Generator }\end{array}$} & Process monitoring & $\begin{array}{l}\text { Steam pressure, condenser pressure, } \\
\text { valve position, turbine and } \\
\text { generator speed }\end{array}$ & Ayaz (2008) \\
\hline & Oil analysis & $\begin{array}{l}\text { Particle counting, wear debris } \\
\text { monitoring, elemental composition } \\
\text { of wear debris }\end{array}$ & $\begin{array}{l}\text { Ahn et al. (1996); Prabhakaran and } \\
\text { Jagga (1999) }\end{array}$ \\
\hline & Vibration monitoring & Vibration & Yan and Goebel (2003) \\
\hline $\begin{array}{l}\text { Passive } \\
\text { Components } \\
\text { (steam } \\
\text { generator } \\
\text { tubing, } \\
\text { RVACS) }\end{array}$ & Nondestructive inspection & Ultrasonic, eddy current, visual & $\begin{array}{l}\text { Sweeney et al. (1993); Meyer et al. } \\
\text { (2013) }\end{array}$ \\
\hline $\begin{array}{l}\text { Liquid-metal- } \\
\text { water Reaction } \\
\text { Pressure Relief } \\
\text { System }\end{array}$ & $\begin{array}{l}\text { Hydrogen detection, leak } \\
\text { detection, pressure }\end{array}$ & Hydrogen, pressure & Kruger et al. (1976) \\
\hline
\end{tabular}


Reactor coolant pumps (RCPs) have received significant research attention because of the significant economic losses during extended plant shutdowns for pump maintenance and replacement. Techniques proposed for centrifugal pumps include vibration monitoring (both frequency and amplitude), pump head monitoring, flow rate monitoring, dynamic pressure analysis, and motor power analysis (Casada 1994; Greene et al. 1995). More recent approaches to pump condition assessment have focused on stressorbased analysis and advanced frequency-based vibration analysis.

Nuclear power plants commonly employ check valves and MOVs. Methods to evaluate the condition of valves online have been under development for decades to relieve mandated offline inspections that require partial disassembly. Techniques proposed for check valves include acoustic emission, ultrasonic inspection, and magnetic flux signature analysis (for instance, Haynes 1990) while motor control center testing (e.g., motor current signature analysis, actuator output torque margin, control switch operation) and monitoring valve parameters (e.g., stem force and torque, motor current and power, switch state sensing) have been proposed for MOV monitoring (for instance, Lewis 1994).

Several online, nondestructive approaches have also been developed for monitoring motor health, including vibration analysis, motor current signature analysis, thermography, and operational monitoring (Hudson 1999). More recently, digital rotor telemetry suites have been developed to directly measure voltage, current, insulation resistance to ground, average winding temperature, and winding hot spot temperature during operation (Maughan and Reschovsky 2010).

The control rod drive system consists of the control rods and the mechanical and electrical systems that control the motion and position of the control rods (e.g., control rod drive mechanism, power and logic cabinets, cables, connectors, and rod position indication system); these systems and components are located both inside and outside containment. Several components with common aging problems, such as cables, coils, rod position indication system, fuses, and power electronics, could contribute to control rod functional failure (Gunther and Sullivan 1991a, b). Improved rod-position indicators (Hashemian et al. 2012) and motor ECA techniques may be applicable for monitoring the different components of the control rod drive system to detect aging-related degradation.

Inspection techniques for passive components have tended to rely on nondestructive approaches (Meyer et al. 2013), with online nondestructive evaluation approaches proposed for long-term monitoring. However, it is unclear if these techniques can be directly applied to passive components such as RVACS or if additional development is needed.

ECA methods for other components (such as steam generator louvers) that may be risk-significant in advanced reactor concepts appear to not have been investigated. As with RVACS, there is a need to determine if available techniques can be leveraged for monitoring the different components of these systems.

\subsection{Estimating Failure Probabilities}

Many approaches to estimating the failure probabilities at future times are available for nuclear power system components (Coble et al. 2012; Coble et al. 2013; Meyer et al. 2013). A common approach involves characterization of the expected lifetime of an average system or component operating in an average environment, under average usage conditions. Component failure probability distributions can be derived through reliability analyses using measured component or system lifetimes (under expected or accelerated 
conditions) (Abernethy 2004). Such an approach does not account for unit-specific factors, such as unit-tounit manufacturing variability, maintenance and service activities, and experienced stresses. Alternative approaches that use degradation analysis to augment reliability analysis and component lifetime data can compensate for the small number of failures seen during accelerated aging tests as equipment becomes more reliable (Lu and Meeker 1993; Chinnam 1999, 2002). The final class of approaches are based on the prediction of reliability at some future point in time based on measurements up to (and including) the current time (Xu and Zhao 2005). Prognostic algorithms use measurements to estimate measures of degradation (sometimes called condition indices), and use information on current condition and stressor levels to extrapolate these degradation measures to a time of interest, $t_{i}$, in the face of stressors. When coupled with knowledge of degradation measures that can result in failure, the prognostic algorithm is able to estimate probability of failure at future times.

Sources of uncertainty at nearly every step in the approach will result in uncertainty in the predicted POF. Some of these sources include measurement uncertainty, inaccuracy in the models that relate measurements to degradation, uncertainty in future stress conditions, inaccuracy in prognostic models to extrapolate degradation measures, and uncertainty in the POF evaluation method. Methods for uncertainty assessment in prognostics are being examined in the research community (Phani et al. 2007; Sankararaman et al. 2011; Solstad and Van Nieuwenhove 2011; Wang 2011; Wang et al. 2012). These range from closed-form solutions to probabilistic approaches such as the bootstrap technique and Monte Carlo simulations. These techniques may be leveraged if possible to calculate the uncertainty in the POF. An open question is approaches to propagating the uncertainty in the POF through the ERM to determine the uncertainty in the predicted risk, although Monte Carlo methods may be a potential approach to achieving this uncertainty propagation.

\subsection{Initial Assessment of Proposed ERM Methodology}

The initial assessment of the ERM methodology uses PRA analysis of the simplified-model AdvSMR design depicted in Figure 2.3. The design only shows frontline components, and supporting systems such as AC and DC electrical power systems, instrumentation, and the details of the reactor trip system are not defined at this stage, for two reasons. First, for currently operating reactors, the reactor trip system is traditionally reliable and typically a low contributor to the nuclear safety risk. It is assumed that future reactor trip systems will be designed to be even more reliable and therefore continue to contribute little to the nuclear safety risk of AdvSMR designs. Second, for currently operating reactors, failures of supporting systems typically can be important contributors to nuclear safety risk; however, we assume that such failures will become a smaller contributor to nuclear risk in future designs because of incorporation of the passive system features and less reliance on supporting systems. Accordingly, a solution of the probabilistic model of the example reactor will yield only failure combinations (i.e., cutsets) associated with failures of frontline components identified in Figure 2.3. These failure combinations are considered to represent dominant failures.

\subsubsection{PRA for Simplified-model AdvSMR}

A full PRA model consists primarily of event trees and fault tree models. However, at this stage in the development and assessment, the focus is on cutsets that might be produced if fault and events trees models were generated. 
A list of 30 cutsets was developed for the simplified-model AdvSMR, representing the dominant cutsets that might be produced if event and fault tree models had been developed and solved. These cutsets use the frontline system components only. Accordingly, this solution yields only failure combinations (i.e., cutsets) associated with failures of the frontline system components identified in one line of our simplified-model AdvSMR power block. Table 3.2 presents a summary of the 30 cutsets used in the analysis. These failure combinations are considered to be a reasonable approximation of the dominant cutsets and define our probabilistic model.

Table 3.2. Assumed Dominant Cutsets for Example AdvSMR Power Block

\begin{tabular}{|c|c|c|c|c|}
\hline Cutset & Initiating Event & \multicolumn{3}{|c|}{$\begin{array}{l}\text { Subsequent Component/System Failures } \\
\end{array}$} \\
\hline$\overline{1 A}$ & $\begin{array}{l}\text { Loss of Electromagnetic } \\
\text { Pump \#1 on Module A }\end{array}$ & $\begin{array}{l}\text { Electromagnetic Pump \#2 } \\
\text { fails to run on Module A }\end{array}$ & $\begin{array}{l}\text { Electromagnetic Pump \#3 } \\
\text { fails to run on Module A }\end{array}$ & $\begin{array}{l}\text { RVACS fails } \\
\text { on Module A }\end{array}$ \\
\hline 2A & Loss of Power & $\begin{array}{l}\text { Emergency Diesel fails to } \\
\text { run }\end{array}$ & RVACS fails on Module A & \\
\hline 3A & $\begin{array}{l}\text { Steam Generator tube } \\
\text { rupture on Module A }\end{array}$ & $\begin{array}{l}\text { Liquid-metal-sodium } \\
\text { reaction pressure relief } \\
\text { fails on Module A }\end{array}$ & $\begin{array}{l}\text { Intermediate Isolation } \\
\text { Valve \# } 1 \text { fails to close on } \\
\text { Module A }\end{array}$ & $\begin{array}{l}\text { RVACS fails } \\
\text { on Module A }\end{array}$ \\
\hline 4A & $\begin{array}{l}\text { Loss of Feedwater Pump } \\
\# 1 \text { on Module A }\end{array}$ & $\begin{array}{l}\text { Feedwater Pump \#2 fails to } \\
\text { run on Module A }\end{array}$ & $\begin{array}{l}\text { Steam Generator louvers } \\
\text { fail to open on Module A }\end{array}$ & $\begin{array}{l}\text { RVACS fails } \\
\text { on Module A }\end{array}$ \\
\hline $5 A$ & $\begin{array}{l}\text { Loss of Intermediate } \\
\text { Loop Pump \#1 on Module } \\
\text { A }\end{array}$ & $\begin{array}{l}\text { Intermediate Loop Pump } \\
\text { \#2 fails to run on Module } \\
\text { A }\end{array}$ & RVACS fails on Module A & \\
\hline 6A & $\begin{array}{l}\text { Loss of Main Feedwater } \\
\text { Pump \#1 }\end{array}$ & $\begin{array}{l}\text { Main Feedwater Pump \#2 } \\
\text { fails to run }\end{array}$ & RVACS fails on Module A & \\
\hline 7A & $\begin{array}{l}\text { Loss of Main Condensate } \\
\text { Pump \#1 }\end{array}$ & $\begin{array}{l}\text { Main Condensate Pump \#2 } \\
\text { fails to run }\end{array}$ & RVACS fails on Module A & \\
\hline 8A & $\begin{array}{l}\text { Rupture of Intermediate } \\
\text { Heat Exchanger tube on } \\
\text { Module A }\end{array}$ & $\begin{array}{l}\text { Feedwater Pump \# } 1 \text { fails } \\
\text { to run on Module A }\end{array}$ & RVACS fails on Module A & \\
\hline 9A & $\begin{array}{l}\text { Rupture of Intermediate } \\
\text { Heat Exchanger tube on } \\
\text { Module A }\end{array}$ & $\begin{array}{l}\text { Feedwater Pump \#2 fails to } \\
\text { run on Module A }\end{array}$ & RVACS fails on Module A & \\
\hline 10A & $\begin{array}{l}\text { Plug or Failure of } \\
\text { RVACS on Modules A } \\
\text { and B due to external } \\
\text { event }\end{array}$ & $\begin{array}{l}\text { Steam Generator louvers } \\
\text { fail to open on Module A }\end{array}$ & $\begin{array}{l}\text { Operator fails to recover } \\
\text { RVACS on Module A }\end{array}$ & \\
\hline 11A & $\begin{array}{l}\text { Steam Generator tube } \\
\text { rupture on Module A }\end{array}$ & $\begin{array}{l}\text { Liquid-metal-sodium } \\
\text { reaction pressure relief } \\
\text { fails on Module A }\end{array}$ & $\begin{array}{l}\text { Intermediate Loop } \\
\text { Isolation Valve \# 2fails to } \\
\text { close on Module A }\end{array}$ & $\begin{array}{l}\text { RVACS fails } \\
\text { on Module A }\end{array}$ \\
\hline 12A & $\begin{array}{l}\text { Loss of Feedwater Pump } \\
\# 2 \text { on Module A }\end{array}$ & $\begin{array}{l}\text { Feedwater Pump \# } 1 \text { fails } \\
\text { to run on Module A }\end{array}$ & $\begin{array}{l}\text { Steam Generator louvers } \\
\text { fail to open on Module A }\end{array}$ & $\begin{array}{l}\text { RVACS fails } \\
\text { on Module A }\end{array}$ \\
\hline 13A & $\begin{array}{l}\text { Loss of Main Feedwater } \\
\text { Pump \#2 }\end{array}$ & $\begin{array}{l}\text { Main Feedwater Pump \#1 } \\
\text { fails to run }\end{array}$ & RVACS fails on Module A & \\
\hline 14A & $\begin{array}{l}\text { Loss of Condensate Pump } \\
\# 2 \text { on Module A }\end{array}$ & $\begin{array}{l}\text { Main Condensate Pump } \\
\text { \#1fails to run on Module A }\end{array}$ & RVACS fails on Module A & \\
\hline 15A & Reactor Transient Trip & $\begin{array}{l}\text { Turbine Bypass valve fails } \\
\text { to open }\end{array}$ & $\begin{array}{l}\text { Steam Generator louvers } \\
\text { fail to open on Module A }\end{array}$ & $\begin{array}{l}\text { RVACS fails } \\
\text { on Module A }\end{array}$ \\
\hline
\end{tabular}


Table 3.2. (cont'd)

\begin{tabular}{|c|c|c|c|c|}
\hline Cutset & Initiating Event & Subsequen & Component/System Failur & \\
\hline 1B & $\begin{array}{l}\text { Loss of Electromagnetic } \\
\text { Pump \#1 on Module B }\end{array}$ & $\begin{array}{l}\text { Electromagnetic Pump \#2 } \\
\text { fails to run on Module B }\end{array}$ & $\begin{array}{l}\text { Electromagnetic Pump \#3 } \\
\text { fails to run on Module B }\end{array}$ & $\begin{array}{l}\text { RVACS fails } \\
\text { on Module B }\end{array}$ \\
\hline 2B & Loss of Power & $\begin{array}{l}\text { Emergency Diesel fails to } \\
\text { run }\end{array}$ & RVACS fails on Module B & \\
\hline 3B & $\begin{array}{l}\text { Steam Generator tube } \\
\text { rupture on Module B }\end{array}$ & $\begin{array}{l}\text { Liquid-metal-sodium } \\
\text { reaction pressure relief } \\
\text { fails on Module B }\end{array}$ & $\begin{array}{l}\text { Intermediate Isolation } \\
\text { Valve \# 1fails to close on } \\
\text { Module B }\end{array}$ & $\begin{array}{l}\text { RVACS fails } \\
\text { on Module B }\end{array}$ \\
\hline 4B & $\begin{array}{l}\text { Loss of Feedwater Pump } \\
\# 1 \text { on Module B }\end{array}$ & $\begin{array}{l}\text { Feedwater Pump \#2 fails to } \\
\text { run on Module B }\end{array}$ & $\begin{array}{l}\text { Steam Generator louvers } \\
\text { fail to open on Module B }\end{array}$ & $\begin{array}{l}\text { RVACS fails } \\
\text { on Module B }\end{array}$ \\
\hline 5B & $\begin{array}{l}\text { Loss of Intermediate } \\
\text { Loop Pump \#1 on Module } \\
\text { B }\end{array}$ & $\begin{array}{l}\text { Intermediate Loop Pump } \\
\# 2 \text { fails to run on Module } \\
\text { B }\end{array}$ & RVACS fails on Module B & \\
\hline 6B & $\begin{array}{l}\text { Loss of Main Feedwater } \\
\text { Pump \#1 }\end{array}$ & $\begin{array}{l}\text { Main Feedwater Pump \#2 } \\
\text { fails to run }\end{array}$ & RVACS fails on Module B & \\
\hline 7B & $\begin{array}{l}\text { Loss of Main Condensate } \\
\text { Pump \#1 }\end{array}$ & $\begin{array}{l}\text { Main Condensate Pump \#2 } \\
\text { fails to run }\end{array}$ & RVACS fails on Module B & \\
\hline 8B & $\begin{array}{l}\text { Rupture of Intermediate } \\
\text { Heat Exchanger tube on } \\
\text { Module B }\end{array}$ & $\begin{array}{l}\text { Feedwater Pump \# } 1 \text { fails } \\
\text { to run on Module B }\end{array}$ & RVACS fails on Module B & \\
\hline 9B & $\begin{array}{l}\text { Rupture of Intermediate } \\
\text { Heat Exchanger tube on } \\
\text { Module A }\end{array}$ & $\begin{array}{l}\text { Feedwater Pump \#2 fails to } \\
\text { run on Module B }\end{array}$ & RVACS fails on Module B & \\
\hline 10B & $\begin{array}{l}\text { Plug or Failure of } \\
\text { RVACS on Modules A } \\
\text { and B due to external } \\
\text { event }\end{array}$ & $\begin{array}{l}\text { Steam Generator louvers } \\
\text { fail to open on Module B }\end{array}$ & $\begin{array}{l}\text { Operator fails to recover } \\
\text { RVACS on Module B }\end{array}$ & \\
\hline 11B & $\begin{array}{l}\text { Steam Generator tube } \\
\text { rupture on Module B }\end{array}$ & $\begin{array}{l}\text { Liquid-metal-sodium } \\
\text { reaction pressure relief } \\
\text { fails on Module B }\end{array}$ & $\begin{array}{l}\text { Intermediate Loop } \\
\text { Isolation Valve \# 2fails to } \\
\text { close on Module B }\end{array}$ & $\begin{array}{l}\text { RVACS fails } \\
\text { on Module A }\end{array}$ \\
\hline 12B & $\begin{array}{l}\text { Loss of Feedwater Pump } \\
\text { \#2 on Module B }\end{array}$ & $\begin{array}{l}\text { Feedwater Pump \# } 1 \text { fails } \\
\text { to run on Module B }\end{array}$ & $\begin{array}{l}\text { Steam Generator louvers } \\
\text { fail to open on Module B }\end{array}$ & $\begin{array}{l}\text { RVACS fails } \\
\text { on Module B }\end{array}$ \\
\hline 13B & $\begin{array}{l}\text { Loss of Main Feedwater } \\
\text { Pump \#2 on }\end{array}$ & $\begin{array}{l}\text { Main Feedwater Pump \#1 } \\
\text { fails to run }\end{array}$ & RVACS fails on Module B & \\
\hline 14B & $\begin{array}{l}\text { Loss of Main Condensate } \\
\text { Pump \#2 }\end{array}$ & $\begin{array}{l}\text { Main Condensate Pump \#1 } \\
\text { fails to run }\end{array}$ & RVACS fails on Module B & \\
\hline 15B & Reactor Transient Trip & $\begin{array}{l}\text { Turbine Bypass valve fails } \\
\text { to open }\end{array}$ & $\begin{array}{l}\text { Steam Generator louvers } \\
\text { fail to open on Module B }\end{array}$ & $\begin{array}{l}\text { RVACS fails } \\
\text { on Module B }\end{array}$ \\
\hline
\end{tabular}

The following assumptions are implicit to the defined cutsets:

- One out of three electromagnetic pumps is required for decay heat removal for cooling involving intermediate heat exchanger.

- One out of two intermediate loop pumps is required for decay heat removal for cooling involving intermediate heat exchanger. 
- One out of two module feedwater pumps is for required for decay heat removal for cooling involving the condenser.

- One out of two power block feedwater pumps is required for decay heat removal for cooling involving the condenser for one or two modules.

- One out of two power block condensate pumps is required for decay heat removal for cooling involving the condenser for two modules.

- Two intermediate pumps are required to run in case of an intermediate heat exchanger tube rupture.

- Either both intermediate loop isolation valves or the liquid-metal-water pressure-relief system must be successful in case of a steam generator tube rupture.

- One emergency diesel generator is assumed for the power block.

- For failure of RVACS caused by external events such as high winds, the opportunity for recovery (e.g., unplug radiating fins) by plant operators was assumed to be possible.

All combinations, but not necessarily all variations of combinations, of failures defined for the simplified-model AdvSMR design are presented within the 30 cutsets.

Table 3.3 presents the initiating event and system component failure probabilities used to initialize the model (i.e., the failure probabilities when the components are as-built). (Some components in this listing actually represent systems, such as RVACS.) Supporting systems such as AC and DC electrical power systems, instrumentation, and the details of the reactor trip system are not defined for the example reactor power block so are not reflected (with a couple of exceptions) in the probabilistic model used in this initial study.

For this preliminary analysis, where available, industry documented failure data (Eide et al. 2007) was used to define initiating event and component failure likelihoods for the key components in the simplified-model AdvSMR design. The first-year values were set to be compatible to mean industry failure rates presented in NUREG/CR-6928; however, latitude was taken in adjusting these values for the example. Specifically, for components where such data is not readily available, assumed failure data was used based on available operational experience and like-kind components.

Initial evaluation of the ERM incorporated assumed time-based event and failure probabilities for each of the initiating events and key components failures of our example AdvSMR power block. These time-based likelihoods assume that the probability of failure increases from the initial probability when equipment is in like-new condition to a maximum probability of failure from component aging, until a scheduled maintenance action is taken. Periodic maintenance intervals are staggered for each component to reflect different operating lifetimes. 
Table 3.3. Initiating Event Frequencies and Component/System Failure Rates used in the Model

\begin{tabular}{|c|c|c|c|}
\hline $\begin{array}{l}\text { Component and Failure } \\
\text { Mode }\end{array}$ & Failure Rate & $\begin{array}{c}\text { Initiator } \\
\text { or System } \\
\text { Failure }\end{array}$ & Assumption/Comments \\
\hline $\begin{array}{l}\text { Electromagnetic pump } \\
\text { - failure to run }\end{array}$ & $3.0 \mathrm{E}-5 / \mathrm{hr}$ & Both & $\begin{array}{l}\text { Assumed unproven for NPP use. Failure rate } \\
\text { somewhat higher than average. }\end{array}$ \\
\hline $\begin{array}{l}\text { RVACS } \\
\text { - failure to function }\end{array}$ & $5.0 \mathrm{E}-7 / \mathrm{hr}$ & Both & $\begin{array}{l}\text { Recovery of RVACS given it plugs was } \\
\text { assumed to be } 1 \mathrm{E}-1\end{array}$ \\
\hline $\begin{array}{l}\text { Intermediate heat exchangers } \\
\text { - tube rupture }\end{array}$ & 8.7E-3/yr & Initiator & $\begin{array}{l}\text { Assumed unproven for NPP use. Failure rate } \\
\text { much higher than average. }\end{array}$ \\
\hline $\begin{array}{l}\text { Intermediate loop isolation } \\
\text { valve } \\
\text { - failure to close }\end{array}$ & 7.0E-3/demand & $\begin{array}{l}\text { System } \\
\text { failure }\end{array}$ & $\begin{array}{l}\text { Assumed to somewhat higher than NPP } \\
\text { average. Motive power undefined. }\end{array}$ \\
\hline $\begin{array}{l}\text { Intermediate loop pumps } \\
\text { - failure to run }\end{array}$ & 2.0E-5/hr & Both & $\begin{array}{l}\text { Failure rate assumed to be near NPP average } \\
\text { for motor driven pumps. }\end{array}$ \\
\hline $\begin{array}{l}\text { Steam generator } \\
\text { - tube rupture }\end{array}$ & 8.7E-2/yr & Initiator & $\begin{array}{l}\text { Assumed to be unproven for NPP use. Failure } \\
\text { rate higher than average. }\end{array}$ \\
\hline $\begin{array}{l}\text { Pressure relief system } \\
\text { - failure to function }\end{array}$ & 2.0E-4/demand & $\begin{array}{l}\text { System } \\
\text { failure }\end{array}$ & $\begin{array}{l}\text { Failure rate assumed to be near NPP average } \\
\text { for pressure relief systems. }\end{array}$ \\
\hline Steam drum & - & - & $\begin{array}{l}\text { Failure of this passive component not modeled. } \\
\text { Assumed to be small contributor to risk. }\end{array}$ \\
\hline $\begin{array}{l}\text { Feedwater pumps } \\
\text { - failure to run }\end{array}$ & $1.0 \mathrm{E}-5 / \mathrm{hr}$ & Both & $\begin{array}{l}\text { Failure rate assumed to be near NPP average } \\
\text { for motor-driven pumps. }\end{array}$ \\
\hline $\begin{array}{l}\text { Passive SG cooling system } \\
\text { - failure to function }\end{array}$ & $5.0 \mathrm{E}-2 / \mathrm{hr}$ & $\begin{array}{l}\text { System } \\
\text { failure }\end{array}$ & $\begin{array}{l}\text { Bounded by operator failure to open steam } \\
\text { generator air flow louvers. }\end{array}$ \\
\hline Turbine generator & - & - & $\begin{array}{l}\text { Assumed to be encompassed by reactor } \\
\text { transient trip events. }\end{array}$ \\
\hline $\begin{array}{l}\text { Turbine bypass valve } \\
\text { - failure to open }\end{array}$ & $1.0 \mathrm{E}-3 / \mathrm{hr}$ & $\begin{array}{l}\text { System } \\
\text { failure }\end{array}$ & Failure rate assumed to be near NPP average. \\
\hline Turbine flow control valve & - & - & $\begin{array}{l}\text { Assumed to be encompassed by reactor } \\
\text { transient trip events. }\end{array}$ \\
\hline $\begin{array}{l}\text { Main feedwater pumps } \\
\text { - failure to run }\end{array}$ & 1.0E-5/hr & Both & $\begin{array}{l}\text { Failure rate assumed to be near NPP average } \\
\text { for motor-driven pumps. }\end{array}$ \\
\hline Main feedwater heater & - & - & $\begin{array}{l}\text { Assumed to be encompassed by reactor } \\
\text { transient trip events. }\end{array}$ \\
\hline $\begin{array}{l}\text { Main condensate pumps } \\
\text { - failure to run }\end{array}$ & $1.0 \mathrm{E}-5 / \mathrm{hr}$ & Both & $\begin{array}{l}\text { Failure rate assumed to be near NPP average } \\
\text { for motor-driven pumps. }\end{array}$ \\
\hline $\begin{array}{l}\text { Emergency diesel generator } \\
\text { - failure to start }\end{array}$ & 2.0E-3/demand & $\begin{array}{l}\text { System } \\
\text { failure }\end{array}$ & $\begin{array}{l}\text { Failure rate assumed to be near NPP average } \\
\text { for emergency diesel generators. }\end{array}$ \\
\hline Reactor transient (trip) & $2.5 \mathrm{E}-1 / \mathrm{yr}$ & Initiator & $\begin{array}{l}\text { Failure rate assumed to be below average for } \\
\text { NPP trips. }\end{array}$ \\
\hline
\end{tabular}

\subsubsection{Initial Results for ERM Assessment}

The risk measure used in this initial assessment is the CDF. For a given time-varying POF for the components in Cutset \#1A, the CDF profile for this cutset is shown in Figure 3.2. As indicated earlier, in the model, the failure rate for the "new" component was set to be comparable to an industry mean failure rate for like-kind components and the end-of-life failure rates were set to be comparable to the 90 percent 
failure rates for like-kind components. When a component is refurbished or replaced (during scheduled maintenance at the end of its nominal service life), the failure rate is returned to the initial value.

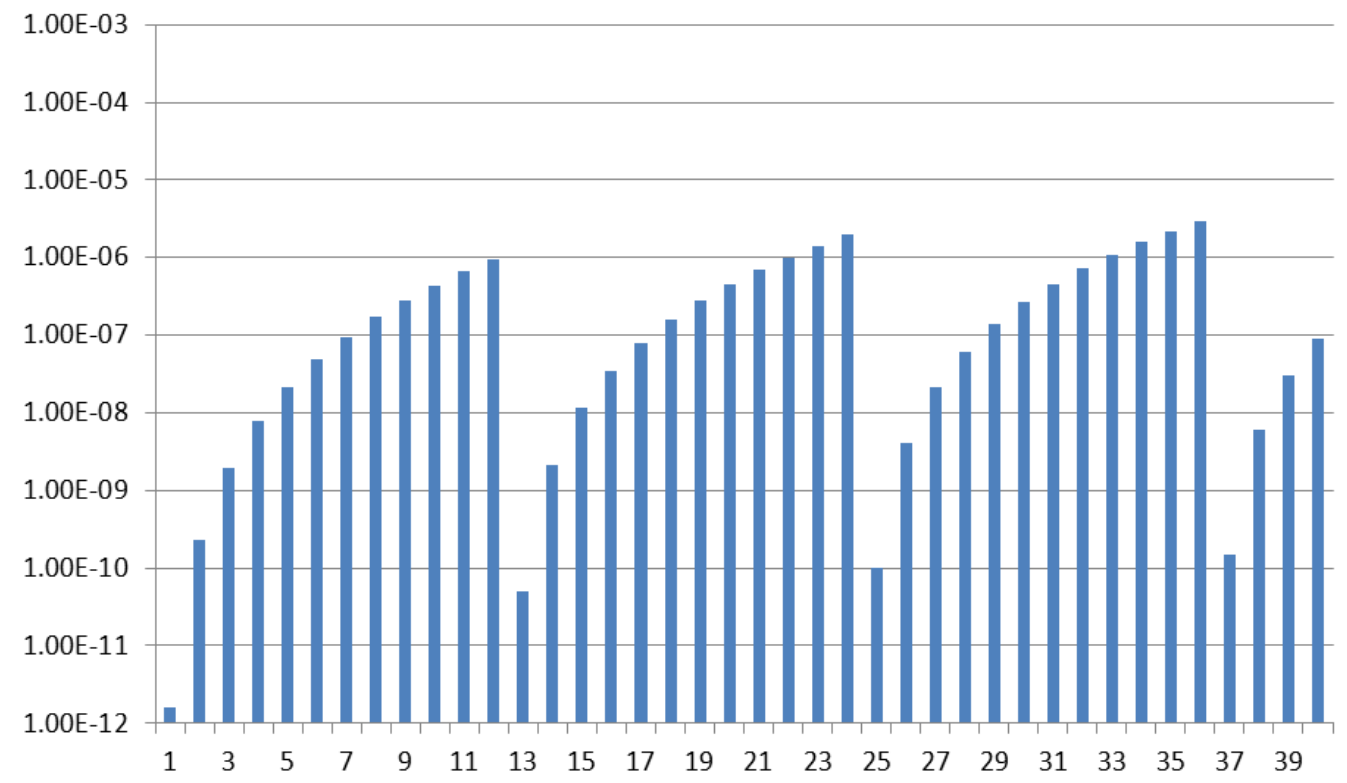

Figure 3.2. Cutset \#1A CDF over Time Based on Time-Varying Event and Failure Probabilities

In the model, two types of initiating events are identified: component-failure-based initiating events (i.e., every initiating event except loss of power, reactor transient trip, and external events that damages RVACS), and non-component-failure-based initiating events. Subsequent events are based on failures assuming a 24-hour mission time (i.e., components must operate on demand and remain operational for 24 hours) or the requirement to operate once on demand during the mission time (e.g., isolation valves that must close once).

The example data shown in Figure 3.2 (as well as data from other cutsets and using different timedependent failure rates) all indicate that varying periodic maintenance intervals and failure rates of the different components failures in each cutset contributes to time-varying risk profiles. For the specific choices made in generating the results in Figure 3.2; the CDF starts (in year 1) at a very low value. With component aging (resulting in increasing POF with age), the CDF increases rapidly until the component (EM pumps) are replaced or repaired. Although these components return to like-new condition, the CDF does not reduce to year-1 values; rather, the aging of other components ensures that the CDF for Cutset \#1A is reduced only marginally. Again, aging-related effects result in the CDF continuing to increase over time, with periodic repairs reducing it. This trend continues until end-of-design life (assumed 40 years) is reached.

The total CDF (computed using all cutsets) is the sum of the individual cutset CDFs. The total CDF over a 40-year reactor power block lifetime for this example is shown in Figure 3.3. In this example, the total CDF varies over approximately three orders of magnitude as the plant and equipment ages. If instead, static failure rates were assumed, and for the sake of the example set at the average rate (over the 
40 years), then the total calculated CDF would be 1.6E-5/yr for each one of the 40 years assumed for the life of the AdvSMR (horizontal red line in Figure 3.3). This, of course, assumes that no changes, such as configuration changes, occur that could impact the calculated CDF. By comparing the static failure rate, indicated by the red line, to the dynamic CDF profile, indicated by the blue bars, information, for instance the time at which the total risk (measured by the CDF in this case) exceeds the static case, may be used to inform replacement, refurbishment, and outage planning decisions.

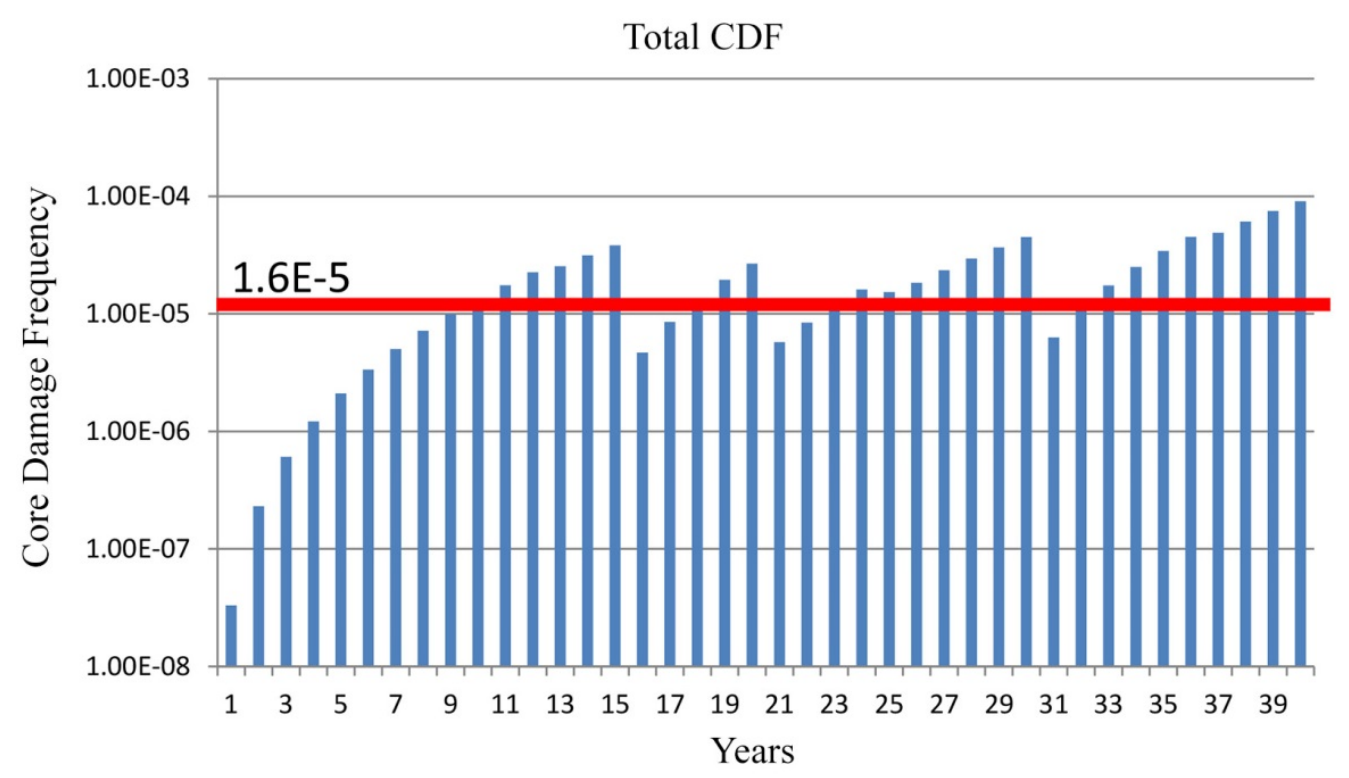

Figure 3.3. Total CDF over Time Based on Time-Varying Event and Failure Probabilities

Preliminary assessment of the initial model where failure probabilities for various components were set to grow faster or slower than the base cases produced changes to the CDF profile (or an absence of significant impact on CDF) that illustrate how such information could be important to inspection and maintenance decisions.

Figure 3.4 presents an example of this. Here, the failure probability of a single component (EM Pump 1 in Module A) is varied, and the total CDF calculated. This information is used to determine the standard deviation of the CDF values at any given time. These values are shown as error bars in the plot and although small, are seen to vary with time as well. This type of analysis, if coupled with formal uncertainty quantification methods, may be able to define the uncertainty in the CDF estimates at future time instants and provide a reasonable level of confidence in the calculated risk values. When coupled with acceptance criteria (i.e., the threshold beyond which the level of risk is considered unacceptable), the uncertainties may be used to determine appropriate maintenance schedules. 


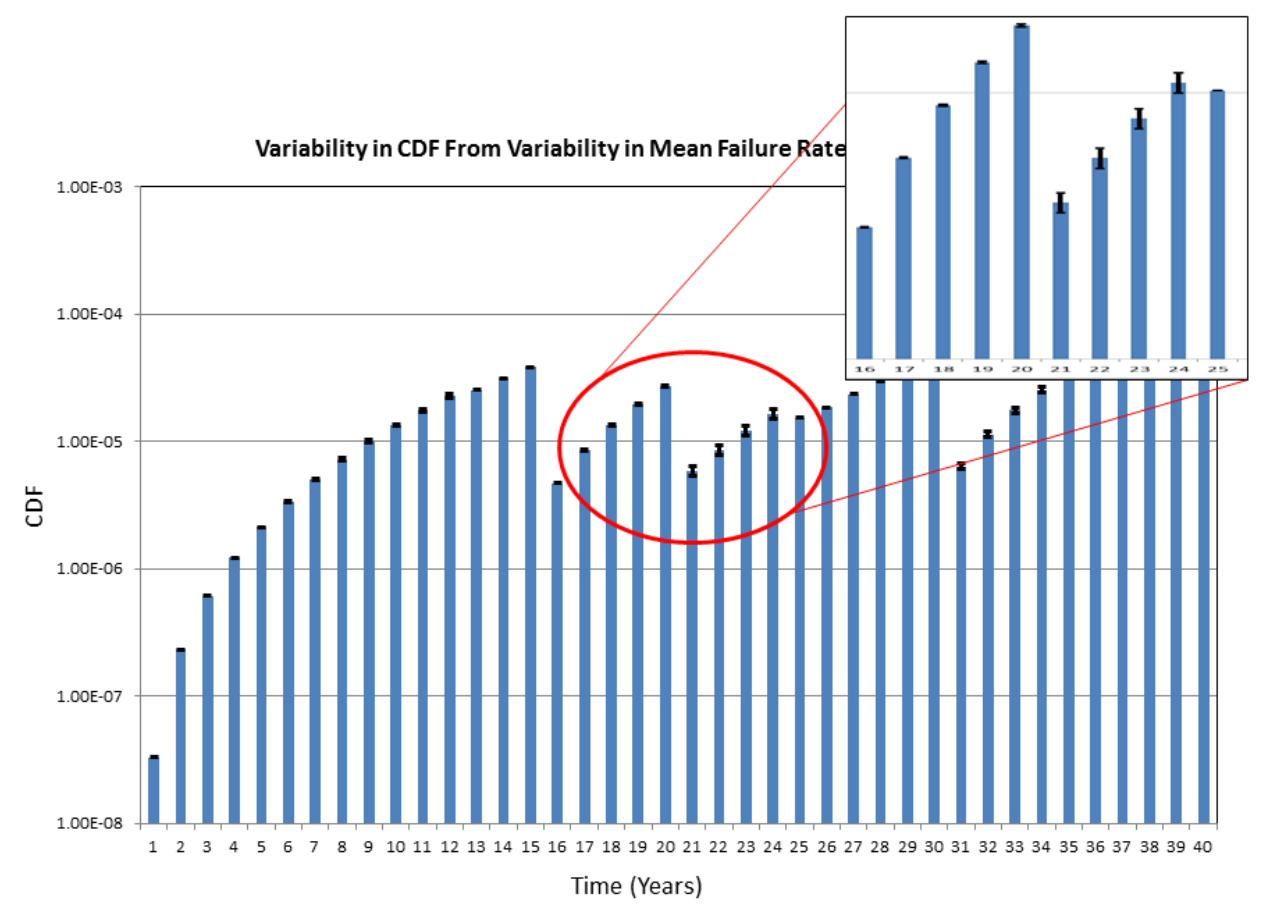

NOTE: The error bars represent the standard deviation of the CDF at any given time instant.

Figure 3.4. Variability in CDF from Variability in the Mean Failure Rate of One Component (EM pump 1 in Module A).

\subsubsection{Importance Analysis from ERM Results}

As noted earlier, existing importance metrics may have reduced usefulness when applied to a model where failure rates and the calculated CDF change over time. When applied to the results in Figure 3.3, we noted that a failure event with a high-importance value at a given point in time might not be as important as a lower importance value at another point in time. We observed one component failure to produce a high RRW value for exactly the years in which the total CDF was very low (e.g., years 1, 3, 25, and 37), so it was unclear how important this component failure was to risk compared with components with lower importance values in years when the CDF was very high (e.g., years 15, 20, 24, 30, and 40).

The importance measure postulated in Section 3.1 was used to analyze the data presented in Figure 3.3. The result of such an analysis is shown Figure 3.5. The results in Figure 3.5 using this definition of importance indicate that the RVACS system is by far the most important system. This seems logical as failure of RVACS is included as the ultimate failure in every cutset and its low failure rate contributes greatly to keeping individual cutset CDFs low. Among the remaining component failures, Figure 3.5 shows the main condensate pumps and intermediate loop pump (IHM pump) failures as being more important than other failures, possibly because these failures contribute to more than one reactor module CDF. 


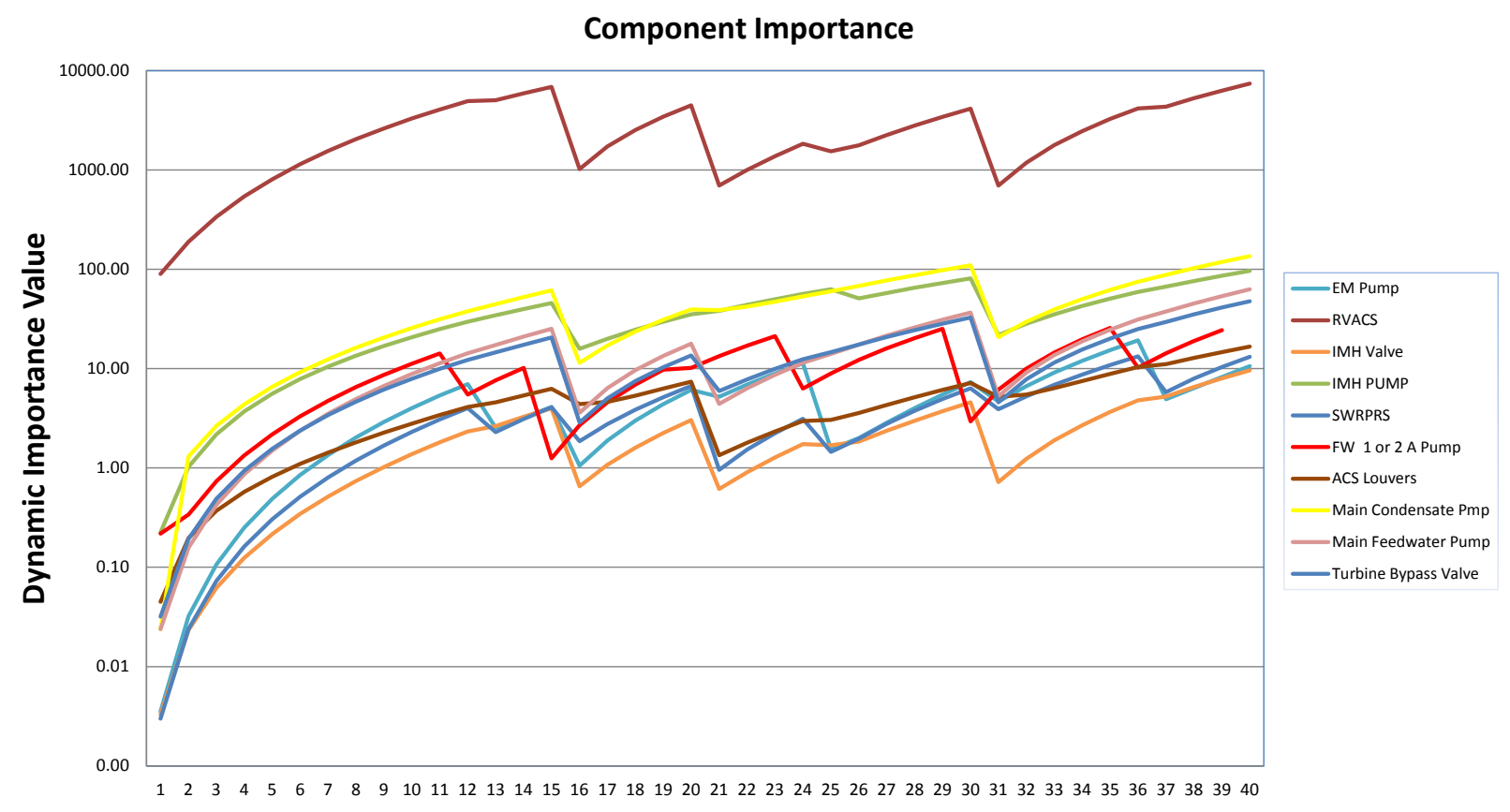

Figure 3.5. Results of Postulated Importance Analysis

\subsection{Discussion}

The current approach to evaluating the risk associated with changing plant configurations does not adequately account for the degraded state of key components and structures. By incorporating real-time information about equipment condition, risk can be more accurately quantified, and O\&M decisions and schedules can potentially be optimized. This is demonstrated by means of simplified PRA modeling of an AdvSMR and examining the changes in CDF over time as a result of the changes in failure probabilities over time of several key components. The resulting information, when compared to traditional PRA analysis, appears to provide useful information for scheduling maintenance activities based on actual degradation condition and consequent failure probabilities. The results of traditional importance analysis indicate that alternate measures of importance are needed to rank the components according to risk, and identify key contributors to the overall risk.

An interesting outcome of this initial analysis was that, using available component failure data, the overall CDF in the example PRA model was orders of magnitude smaller than those generally accepted for currently operating reactors. This is indicated by the CDF value corresponding to the "as-new" components in the first year of operation (Figure 3.3). This is likely because of the small number of key components used in the PRA modeling as well as the use of passive safety features in AdvSMRs. However, this is an expected feature in AdvSMR PRA modeling, as typical risk measures such as CDF are expected to be lowered because of the inclusion of passive safety mechanisms. For example, the latest publically available PRA results for PRISM present accident sequence CDFs in the range of $10^{-8}$ to $10^{-12}$, for a total CDF on the order of $10^{-8}$ (NRC 1994). Although the CDF increases over time in the example presented in Figure 3.3 (and eventually exceeds levels generally accepted for operating reactors), it is because of a potentially inflated rate of change of the probability of failure over time. 
When combined with the fact that enhanced fuels planned for use in AdvSMRs may preclude significant fuel failure, the ability to use CDF as a meaningful measure of risk may be reduced. New, non-traditional risk measures will need to be identified that support the economic and production goals of AdvSMRs, in addition to safety goals. Along with identifying appropriate risk measures, criteria need to be established to assess the acceptability of plant configurations based on risk results (Puglia and Atefi 1995). Establishing acceptance criteria for different risk measures is an operational issue that will be considered in conjunction with the development of supervisory control and O\&M planning algorithms, although site-specific acceptance criteria will likely need to be developed by utilities and regulators.

Additional evaluations of the postulated importance measure are also needed. In addition, alternative importance measures that can provide diagnostic information that can be valuable in informing equipment-related planning and maintenance activities are also needed.

An important aspect of ERM that has been neglected in the foregoing example is the inclusion of uncertainty within the ERM framework. Several sources of uncertainty exist when estimating the probability of failure, including uncertainty regarding the specific condition of the component, uncertainty in the probability of failure, and uncertainty in the time-to-failure. While some of these (such as uncertainty in the POF) are addressed at a rudimentary level in the preliminary ERM methodology described above by means of the mean failure rate and rate of change of failure probability, these are by no means comprehensive and need to be further studied. This, along with the use of non-traditional risk measures, will be examined next. 



\subsection{Summary}

Enhanced risk monitors that integrate ECA and prognostics information to calculate time-dependent failure probabilities have the potential to enable real-time decisions about stress relief for susceptible equipment while supporting effective maintenance planning. As a result, ERMs are expected to improve the safety, availability, and affordability of AdvSMRs.

An initial methodology for integrating time-dependent failure probabilities into risk monitors was developed. The methodology was evaluated using a hypothetical PRA model from a simplified model of a liquid-metal-cooled AdvSMR. Component failure data from industry compilation of failures of components similar to those in the simplified AdvSMR model were used to initialize the PRA model. By using time-dependent probability of failure that grows from the initial probability when equipment is in like-new condition to a maximum probability of failure, which occurs before a scheduled maintenance action that restores or repairs the component to "as-new" condition, we computed and analyzed the changes in CDF over time.

The results indicate that, using the proposed methodology for ERM, as the failure probabilities and failure rates change over time, the CDF changes over time. Repairs or replacements (bringing the components to as-new condition) reduce the risk, although aging of other components may still drive the overall risk higher.

Importance analysis of the results showed that traditional measures of importance, such as risk achievement worth, appear to be less useful when applied to a model where failure rates and the calculated CDF change over time. As a consequence, we proposed a new importance measure that considers the relative importance of the event to the total CDF as well as the value of total CDF itself. This proposed importance measure appears to improve the ability to distinguish between risk-importance of components under time-varying failure probabilities.

In addition, we conducted a study on the state of ECA for AdvSMRs, to identify technologies that may be leveraged to gather experimental data for use in evaluating the ERM framework. This study indicated that, while several ECA techniques exist for components used in current plants (which may be leveraged for similar components planned for AdvSMRs), techniques are as yet unproven for components (such as electromagnetic pumps) that are specifically designed for use in advanced reactors or AdvSMRs.

Ongoing work in developing the ERM will focus on (1) methods to directly incorporate equipment condition assessment for key components in the risk monitor; (2) identification of economic and other risk measures, in addition to the traditional safety measures; (3) developing PRA models that account for changing load and demand conditions (possibly resulting in changing success criteria); and (4) incorporation and integration of uncertainty related to probability of failure and equipment condition monitoring.

Currently, the traditional risk measure of core damage frequency is being used for initial framework development and testing; however, future work will investigate non-safety-related risk measures, such as economic risk. Additional evaluations of the postulated importance measure are also needed. In addition, alternative importance measures that can provide diagnostic information that can be valuable in informing equipment-related planning and maintenance activities are also needed. 
An important aspect of ERM is the inclusion of uncertainty within the ERM framework. Several sources of uncertainty exist when estimating the probability of failure, including uncertainty regarding the specific condition of the component, uncertainty in the probability of failure, and uncertainty in the timeto-failure. These sources of uncertainty will need to be accounted for in the ERM methodology. 


\subsection{References}

Abernethy RB. 2004. The New Weibull Handbook. Robert B. Abernethy, North Palm Beach, Florida.

Abram T and S Ion. 2008. "Generation-IV Nuclear Power: A Review of the State of the Science." Energy Policy 36(12):4323-4330.

Ahn HS, ES Yoon, DG Sohn, OK Kwon, KS Shin and CH Nam. 1996. "Practical Contaminant Analysis of Lubricating Oil in a Steam Turbine-Generator." Tribology International 29(2):161-168.

Anheier NC, JD Suter, HA Qiao, ES Andersen, EJ Berglin, M Bliss, BD Cannon, R Devanathan, A Mendoza and DM Sheen. 2013. Technical Readiness and Gaps Analysis of Commercial Optical Materials and Measurement Systems for Advanced Small Modular Reactors SMR/ICHMI/PNNL/TR2013/04; PNNL-22622, Rev. 1, Pacific Northwest National Laboratory, Richland, Washington.

Apostolakis G. 2000. "The Nuclear News Interview—Apostolakis: On PRA." Nuclear News 43(3):2731.

Arcella FG, FH Bednar, JJ Schreurs and JM Forker. 1994. "Online Valve Diagnostic Monitoring System." Patent Number 5,329,465.

Arjas E and J Holmberg. 1995. "Marked Point Process Framework for Living Probabilistic Safety Assessment and Risk Follow-up." Reliability Engineering \& System Safety 49(1):59-73.

Ayaz E. 2008. "Component-Wide and Plant-Wide Monitoring by Neural Networks for Borssele Nuclear Power Plant." Energy Conversion and Management 49:3721-3728.

Baumhardt RJ and RA Bechtold. 1987. "Five Years Operating Experience at the Fast Flux Test Facility." In ANS/ENS International Conference on Fast Breeder Reactor Systems: Experience Gained and Path to Power Generation. September 13, 1987, Richland, Washington.

Casada D. 1994. "Detection of Pump Degradation." In 22nd Water Reactor Safety Information Meeting. October 24-26, 1994, Bethesda, Maryland.

Chai J, RH Lyon and JH Lang. 1994. "Non-invasive Diagnostics of Motor-operated Valves." In Proceedings of 1994 American Control Conference (ACC '94), pp. 2006-2012. June 29-July 1, 1994, Baltimore, Maryland. IEEE, Piscataway, New Jersey.

Chinnam RB. 1999. "On-line Reliability Estimation of Individual Components, Using Degradation Signals." IEEE Transactions on Reliability 48(4):403-412.

Chinnam RB. 2002. "On-line Reliability Estimation for Individual Components Using Statistical Degradation Signal Models." Quality and Reliability Engineering International 18(1):53-73.

Cho S and SH Hong. 1998. "The Magnetic Field and Performance Calculations for an Electromagnetic Pump of a Liquid Metal." Journal of Physics D: Applied Physics 31(20):2754.

Coble JB, GA Coles, P Ramuhalli, RM Meyer, EJ Berglin, DW Wootan and MR Mitchell. 2013. Technical Needs for Enhancing Risk Monitors with Equipment Condition Assessment for Advanced Small Modular Reactors. PNNL-22377 Rev. 0; SMR/ICHMI/PNNL/TR-2013/02, Pacific Northwest National Laboratory, Richland, Washington. 
Coble JB, P Ramuhalli, LJ Bond, JW Hines and BR Upadhyaya. 2012. Prognostics and Health Management in Nuclear Power Plants: A Review of Technologies and Applications. PNNL-21515, Pacific Northwest National Laboratory, Richland, Washington.

Daigle M and K Goebel. 2010. "Model-Based Prognostics Under Limited Sensing." In 2010 IEEE Aerospace Conference, pp. 1-12. March 6-13, 2010, Big Sky, Montana. DOI 10.1109/AERO.2010.5446822. IEEE, Piscataway, New Jersey.

Daw J, J Rempe, P Ramuhalli, R Montgomery, HT Chien, B Tittmann and B Reinhardt. 2012. NEET InPile Ultrasonic Sensor Enablement-FY 2012 Status Report. INL/EXT-12-27233, PNNL-21835, Idaho National Laboratory, Idaho Falls, Idaho.

Eide SA, TE Wierman, CD Gentillon, DM Rasmussen and CL Atwood. 2007. Industry-Average Performance for Components and Initiating Events at U.S. Commercial Nuclear Power Plants. NUREG/CR-6928, INL/EXT-06-11119, U.S. Nuclear Regulatory Commission, Washignton, D.C.

EPRI. 2009. Program on Technology Innovation: Prognostic Application for the Power Industry. Report 1018245, Electric Power Research Institute, Inc. (EPRI), Palo Alto, California.

EPRI. 2011. "Basics of Nuclear Power Plant Probabilistic Risk Assessment." Electric Power Research Institute (EPRI), Palo Alto, California. Presented at Fire PRA Workshop 2011 in San Diego, California, and Jacksonville, Florida.

Eren L, B Onur and MJ Devaney. 2005. IMTC'05, Proceedings of the IEEE Instrumentation and Measurement Technology Conference, 2, pp. 834-837. May 16-19, 2005, Ottawa, Ontario, Canada. IEEE, Piscataway, New Jersey.

Fulwood RR and RE Hall. 1988. Probabilistic Risk Assessment in the Nuclear Power Industry: Fundamentals and Applications. Pergamon Press. ISBN 0080363628.

Gomes JPP, BC Ferreira, D Cabral, RKH Galvão and T Yoneyama. 2010. "Health Monitoring of a Pneumatic Valve Using a PIT Based Technique." In Annual Conference of the Prognostics and Health Management Society. October 10-16, 2010, Portland, Oregon. PHM Society. Available at http://www.phmsociety.org/sites/phmsociety.org/files/phm_submission/2010/phmc_10_054.pdf.

Granjon P. 2011. "Condition Monitoring of Motor-Operated Valves in Nuclear Power Plants." In 8th International Conference on Condition Monitoring and Machinery Failure Prevention Technologies (CM/MFPT 2011), pp. 109-119. June 20-22, 2011, Cardiff, Wales. Curran Assoc., Red Hook, New York.

Greene RH, DA Casada, CW Ayers and CC Southmayd. 1995. Detection of Pump Degradation. NUREG/CR-6089, ORNL-6765, U.S. Nuclear Regulatory Commission, Washington, D.C.

Gross KC, RM Singer and KE Humenik. 1993. "Expert System for Online Surveillance of Nuclear Reactor Coolant Pumps." Patent Number 5,223,207.

Guidez J, L Martin, SC Chetal, P Chellapandi and B Raj. 2008. "Lessons Learned from Sodium Cooled Fast Reactor Operation and Their Ramifications for Future Reactors with Respect to Enhanced Safety and Reliability." Nuclear Technology 164(2):207-220. 
Gunther W and K Sullivan. 1991a. Aging Mechanisms in the Westinghouse PWR (Pressurized Water Reactor) Control Rod Drive System. BNL-NUREG-45748, Brookhaven National Laboratory, Upton, New York.

Gunther W and K Sullivan. 1991b. "Detecting and Mitigating Rod Drive Control System Degradation in Westinghouse PWRs." IEEE Transactions on Nuclear Science 38(6):1760-1765.

Haasl D, J Young and W Cramond. 1988. Probabilistic Risk Assessment Course Documentation. NUREG/CR-4350, U.S. Nuclear Regulatory Commission, Washington, D.C.

Hashemian HM, GW Morton, SD Caylor and JR McCulley. 2012. "On-Line Condition Monitoring and Diagnostics for Rod Control and Rod Position Indication Systems in Nuclear Reactors." In 8th International Topical Meeting on Nuclear Plant Instrumentation, Control and Human Machine Interface Technologies, NPIC\&HMIT 2012. July 22-26, 2012, San Diego, California. American Nuclear Society.

Haynes HD. 1990. "Evaluation of Check Valve Monitoring Methods." In Proceedings of the U.S. Nuclear Regulatory Commission, Seventeenth Water Reactor Safety Information Meeting, pp. 39-58. October 23-25, 1989, Rockville, Maryland. U.S. Nuclear Regulatory Commission, Washington, D.C.

Hines JW, J Garvey, J Preston and A Usynin. 2008. "Tutorial: Empirical Methods for Process and Equipment Prognostics." In 53rd Annual Reliability and Maintainability Symposium (RAMS), 2008 Proceedings. January 28-31, 2008, Las Vegas, Nevada.

Hudson B. 1999. "HV Motor Condition Monitoring-The End User's View." In IEE Colloquium Design, Operation and Maintenance of High Voltage (3.3 kV to 11 kV) Electric Motors for Process Plant, pp. 7/17/15. September 30, 1999, Glasgow, United Kingdom. DOI 10.1049/ic:19990823. IEE, London.

Jarrell DB, DR Sisk and LJ Bond. 2004. "Prognostics and Conditioned-Based Maintenance: A New Approach to Precursive Metrics." Nuclear Technology 145(3):275-286.

Jung JC and PH Seong. 2006. "An Improved Method for Reactor Coolant Pump Abnormality Monitoring Using Power Line Signal Analysis." Nuclear Engineering and Design 236(1):57-62.

Kafka P. 2008. "Probabilistic Risk Assessment for Nuclear Power Plants." In Handbook of Performability Engineering, pp. 1179-1192 ed: KB Misra. Ch. 71. Springer, London.

Kang S, S Park, D Lee and Y Kim. 2006. "Motor Control Center (MCC) Based Technology Study for Safety-Related Motor Operated Valves." Nuclear Engineering and Technology 38(2):155-162. Special Issue on ICAPP '05.

Karpenko M and N Sepehri. 2002. "Neural Network Classifiers Applied to Condition Monitoring of a Pneumatic Process Valve Actuator." Engineering Applications of Artificial Intelligence 15:273-283.

Koo IS and WW Kim. 2000. "The Development of Reactor Coolant Pump Vibration Monitoring and a Diagnostic System in the Nuclear Power Plant." ISA Transactions 39(3):309-316.

Korkua S, H Jain, W-J Lee and C Kwan. 2010. "Wireless Health Monitoring System for Vibration Setection of Induction Motors." In 2010 IEEE Industrial and Commercial Power Systems Technical Conference, I\&CPS 2010, pp. 1-6. May 9-13, 2010, Tallahassee, Florida. DOI 10.1109/ICPS.2010.5489899. IEEE, Piscataway, New Jersey. 
Kothamasu R, SH Huang and WH VerDuin. 2006. "System Health Monitoring and Prognostics - A Review of Current Paradigms and Practices." International Journal of Advanced Manufacturing Technology 28:1012-1024.

Kruger GB, TB Murdock, E Rodwell and JO Sane. 1976. "Design of the US-CRBRP Sodium/Water Reaction Pressure Relief System." In Second Joint US/USSR Seminar on the Development of SodiumCooled Fast Breeder Steam Generators. July 26, 1976, USSR. CONF-760735-2.

Kueck JD, JC Criscoe and NM Burstein. 1992. "Assessment of Valve Actuator Motor Rotor Degradation by Fourier Analysis of Current Waveform." IEEE Transactions on Energy Conversion 7(3):460-469.

Lewis J. 1994. "Innovative Testing of Motor Operated Valves." In Proceedings of the 1994 Nuclear Science Symposium and Medical Imaging Conference, pp. 1098-1101 Vol.3. October 30-November 5, 1994, Norfolk, Virginia. DOI 10.1109/NSSMIC.1994.474652. IEEE, Piscataway, New Jersey.

Lu CJ and WO Meeker. 1993. "Using Degradation Measures to Estimate a Time-to-Failure Distribution." Technometrics 35(2):161-174.

Maruthi GS and KP Vittal. 2005. "Electrical Fault Detection in Three Phase Squirrel Cage Induction Motor by Vibration Analysis using MEMS Accelerometer." In International Conference on Power Electronics and Drives Systems (PEDS 2005) pp. 838-843. November 28-December 1, 2005, Kualu Lumpur, Malaysia. DOI 10.1109/PEDS.2005.1619804. IEEE, Piscataway, New Jersey.

Maughan CV and JM Reschovsky. 2010. "Advances in Motor and Generator Rotor Health." In 2010 IEEE International Symposium on Electrical Insulation (ISEI 2010), pp. 1-4. June 6-9, 2010, San Diego, California. DOI 10.1109/ELINSL.2010.5549730. IEEE, Piscataway, New Jersey.

McShane JL and NH Ulerich. 1992. "System and Method for Valve Monitoring Using Pipe-Mounted Ultrasonic Transducers." Patent Number 5,115,672.

Meyer RM, JB Coble, EH Hirt, P Ramuhalli, MR Mitchell, DW Wootan, EJ Berglin, LJ Bond and J Henager C.H. 2013. Technical Needs for Prototypic Prognostic Technique Demonstration for Advanced Small Modular Reactor Passive Components. PNNL-22488 Rev. 0, SMR/ICHMI/PNNL/TR-2013/01, Pacific Northwest National Laboratory, Richland, Washington.

Mukhopadhyay S and S Chaudhuri. 1995. "A Feature-Based Approach to Monitor Motor-Operated Valves Used in Nuclear Power Plants." IEEE Transactions on Nuclear Science 42(6):2209-2220.

Nakamura T and M Terada. 1985. "Development of Leak Monitoring System for Pressurizer Valves." Progress in Nuclear Energy 15:175-179.

NRC. 1994. Preapplication Safety Evaluation Report for the Power Reactor Innovative Small Module (PRISM) Liquid-Metal Reactor. NUREG-1368, U.S. Nuclear Regulatory Commission (NRC), Washington, D.C.

NRC. 2012. Probabilistic Risk Assessment (PRA). U.S. Nuclear Regulatory Commission (NRC). Washington, D.C. Accessed October 17, 2012. Available at http://www.nrc.gov/about-nrc/regulatory/riskinformed/pra.html (last updated March 29, 2012). 
NRC. Undated. "Tutorial on Probabilistic Risk Assessment (PRA)." U.S. Nuclear Regulatory Commission (NRC), Washington, D.C. http://www.nrc.gov/about-nrc/regulatory/risk-informed/rpp/pratutorial.pdf.

Papazoglou IA. 1998. "Mathematical Foundations of Event Trees." Reliability Engineering and System Safety 61(3):169-183.

Pázsit I and GT Analytis. 1980. "Theoretical Investigation of the Neutron Noise Diagnostics of TwoDimensional Control Rod Vibrations in a PWR." Annals of Nuclear Energy 7(3):171-183.

Phani KK, D Sanyal and AK Sengupta. 2007. "Estimation of Elastic Properties of Nuclear Fuel Material Using Longitudinal Ultrasonic Velocity - A New Approach." Journal of Nuclear Materials 366(12):129-136.

Prabhakaran A and CR Jagga. 1999. "Condition Monitoring of Steam Turbine-Generator through Contamination Analysis of Used Lubricating Oil." Tribology International 32(3):145-152.

Puglia WJ and B Atefi. 1995. "Examination of Issues Related to the Development and Implementation of Real-Time Operational Safety Monitoring Tools in the Nuclear Power Industry." Reliability Engineering and System Safety 49(2):189-199.

Razzaque MM, MB Pate and HN Shapiro. 1989. "A Novel Concept of Passive Shutdown Heat Removal in Advanced Nuclear Reactors - Applications to PRISM and MHTGR." Annals of Nuclear Energy 16(9):483-486.

Sankararaman S, Y Ling, C Shantz and S Mahadevan. 2011. "Uncertainty Quantification in Fatigue Crack Growth Prognosis." International Journal of Prognostics and Health Management 2(001).

Schwabacher M. 2005. "A Survey of Data-Driven Prognostics." In InfoTech at Aerospace: Advancing Contemporary Aerospace Technologies and Their Integration, pp. 887-891. September 26-29, 2005, Arlington, Virginia. American Institute of Aeronautics and Astronautics Inc., Reston, Virginia.

Schwabacher M and K Goebel. 2007. "A Survey of Artificial Intelligence for Prognostics." In Artificial Intelligence for Prognostics - AAAI Fall Symposium, pp. 107-114. November 9-11, 2007, Arlington, Virginia. American Association for Artificial Intelligence, Menlo Park, California.

Seker S, E Ayaz and E Turkcan. 2003. "Elman’s Recurrent Neural Network Applications to Condition Monitoring in Nuclear Power Plant and Rotating Machinery." Enginering Applications of Artificial Intelligence 16:647-656.

Sharp ME. 2012. Prognostic Approaches Using Transient Monitoring Methods. Ph.D. Thesis, University of Tennessee, Knoxville, Tennessee. Available at http://trace.tennessee.edu/utk_graddiss/1431.

Smith CL, VN Shah, T Kao and GE Apostolakis. 2001. Incorporating Aging Effects into Probabilistic Risk Assessment - A Feasibility Study Utilizing Reliability Physics Models. NUREG/CR-5632, U.S. Nuclear Regulatory Commission, Washington, D.C.

Solstad S and R Van Nieuwenhove. 2011. "Instrument Capabilities and Developments at the Halden Reactor Project." Nuclear Technology 173(1):78-85. 
Stegemann D, W Reimche, U Sudmersen, O Pietsch and Y Liu. 1998. "Monitoring and Vibrational Diagnostic of Rotating Machinery in Power Plants." In Proceedings of the First IEE/IMechE International Conference on Power Station Maintenance - Profitability Through Reliability pp. 39-44. March 30-April 1, 1998, Edinburgh, United Kingdom. IEE, London.

Sweeney FJ, DG Carroll, C Chen, C Crane, R Dalton, JR Taylor, S Tosunoglu and T Weymouth. 1993. "Designs for Remote Inspection of the ALMR Reactor Vessel Auxiliary Cooling System (RVACS)." In Fifth Topical Meeting on Robotics and Remote Handling. April 26-29, 1993, Knoxville, Tennessee.

Thirumalai M, PA Kumar, K Jayagopi, V Prakash, C Anandbabu, P Kalyanasundaram and G Vaidyanathan. 2010. "Vibration Diagnostics as NDT Tool for Condition Monitoring in Power Plants." In Proceedings of the National Seminar \& Exhibition on Non-Destructive Evaluation (NDE 2009), pp. 50-55. December 10-12, 2009, Tiruchy, India.

Thomson WT and M Fenger. 2001. "Current Signature Analysis to Detect Induction Motor Faults." IEEE Industry Applications Magazine 7(4):26-34.

Trutt FC, J Sottile and JL Kohler. 2002. "Online Condition Monitoring of Induction Motors." IEEE Transactions on Industry Applications 38(6):1627-1632.

Upadhyaya BR, M Naghedolfeizi and B Raychaudhuri. 1994. "Residual Life Estimation of Plant Components." P/PM Technology June:22-29.

Vesely W, F Goldberg, N Roberts and D Haasl. 1981. Fault Tree Handbook. NUREG-0492, U.S. Nuclear Regulatory Commission, Washington, D.C.

Vesely WE, TC Davis, RS Denning and N Saltos. 1983. Measures of Risk Importance and Their Applications. NUREG/CR-3385, BMI-2103, U.S. Nuclear Regulatory Commission, Washington, D.C.

Vesely WE and AJ Wolford. 1988. "Risk Evaluations of Aging Phenomena: The Linear Aging Reliability Model and Its Extensions." Nuclear Engineering and Design 108:179-185.

Vitkovskii IV, VG Danilin, VA Neverov, YL Revyakin and PY Chaika. 1988. "Electric Strength of Electromagnetic Pump Insulation During Thermoradiation Aging." Soviet Atomic Energy 67(5):824-828.

Wallace CJ, GM West, GJ Jahn, SDJ MacArthur, D Towle and G Buckley. 2010. "Control Rod Monitoring of Advanced Gas-Cooled Reactors." In Seventh American Nuclear Society International Topical Meeting on Nuclear Plant Instrumentation, Control, and Human-Machine Interface Technologies. November 7-11, 2010, Las Vegas, Nevada. American Nuclear Society.

Wang H. 2011. "Decision of Prognostics and Health Management Under Uncertainty." International Journal of Computer Applications 13(4):1-5.

Wang P, BD Youn and C Hu. 2012. "A Generic Probabilistic Framework for Structural Health Prognostics and Uncertainty Management." Mechanical Systems and Signal Processing 28:622-637.

Weaver KD, JS Herring and PE MacDonald. 2001. "A Comparison of Long-Lived, Proliferation Resistant Fast Reactors." In International Conference on Back-End of the Fuel Cycle: From Research to Solution (GLOBAL 2001). Idaho National Engineering and Environmental Laboratory, Idaho Falls, Idaho. 
Woloshun KA, V Watts and N Li. 2004. Lead-Bismuth Eutectic as Advanced Reactor Coolant:

Operational Experience. LA-UR-04-3925, Los Alamos National Laboratory, Los Alamos, New Mexico.

Wu JS and GE Apostolakis. 1992. "Experience with Probabilistic Risk Assessment in the Nuclear Power Industry." Journal of Hazardous Materials 29(3):313-345.

Xu D and W Zhao. 2005. "Reliability Prediction Using Multivariate Degradation Data." In Annual

Reliability and Maintainability Symposium (RAMS 2005), pp. 337-341. January 24-27, 2005, Alexandria, Virginia. IEEE, Piscataway, New Jersey.

Yan W and KF Goebel. 2003. "Sensor Validation and Fusion for Gas Turbine Vibration Monitoring." In System Diagnosis and Prognosis: Security and Condition Monitoring Issues III, Proceedings of SPIE, Volume 5107, pp. 106-117. April 21, 2003, Orlando, Florida. DOI 10.1117/12.487206. The International Society for Optical Engineering, Bellingham, Washington.

Yoshikawa H, M Yang, M Hashim, M Lind and Z Zhang. 2011. "Design of Risk Monitor for Nuclear Reactor Plants." Nuclear Safety and Simulation 2(3):266-274. 

Appendix A

\section{Sodium Fast Reactors Overview}





\section{Appendix A}

\section{Sodium Fast Reactors Overview}

The sodium fast reactor (SFR) features very high core power densities, high reactor outlet temperatures, low system pressure, and a fast neutron spectrum. An advantage of sodium coolant is its relatively high heat capacity, which protects against overheating during reactor transients and accidents. While the fast neutron spectrum results in large fluences for internal core and reactor vessel components, it also enables fissile and fertile materials to be used considerably more efficiently than thermal spectrum reactors with once-through fuel cycles. Some of the SFR designs, like the super-safe, small and simple (4S) reactor and unique traveling wave reactor (TWR) are optimized for power generation over long periods of time (10-40+ years) without refueling.

The primary coolant system can either be arranged in a pool layout (a common approach, where all primary system components are housed in a single vessel), or in a compact loop layout (favored in Japan). Domestic SFR designs (e.g., PRISM, TWR) use a pool-type reactor vessel design containing the reactor core, primary heat exchanger, and electromagnetic (EM) pump(s). The Japanese 4S reactor design uses a reactor vessel with a loop design (similar to the Fast Flux Test Facility [FFTF]) containing just the reactor core; the primary heat exchanger(s)/pumps are connected by piping to the reactor vessel. An inert cover gas system is used to prevent sodium exposure to air and/or water and to support the reactor vessel, reactor containment vessel, heat exchangers, and steam generator. Under accident conditions, complete passive cooling of the reactor vessel is available through natural convection in the primary loop with air blowers cooling a sodium-air heat exchanger. In general, all penetrations into the reactor vessel occur at the top of the vessel.

Although there are several SFR designs, the general design and operating parameters are similar. The long refueling reactors (such as $4 \mathrm{~S}$ and TWR) on the order of 20-40+ years will require long-life components with the hope that routine maintenance is limited. The shorter refueling reactors (such as PRISM) on the order of 1.5+ years require fuel exchange operations that likely will allow some minimal maintenance to be performed. EM pumps are generally used to pump liquid sodium. Most designs are opting to use a helical coil steam generator design. The $4 \mathrm{~S}$ reactor uses a unique reactive control mechanism.

Active features in SFRs that may be risk-significant include:

- Reactor control mechanisms - Drives located outside reactor vessel with rod extending into vessel. May be both control and shutdown rods. May be very slow movement over long time periods.

- Pumps - Pumping fluids/gas to various reactor systems including heat exchanger (two loops), cover gas, and turbine/compressor unit. Sodium pumps in reactor vessels are typically EM pumps with no moving parts.

- Heaters - Inside and outside reactor vessel. Heat is required to liquefy sodium during initial startup and maintenance periods. In many cases, this may look like a passive device.

- Turbine/compressor - Separate unit connected to steam generator via piping. Under pressure during operation. 
- Valves - Outside of reactor vessel. May include dampers on air circulators.

- Fuel handling mechanisms - For reactors with temporary fuel storage in reactor vessel.

A review of the operating experience of SFRs reveals problems with mechanical sodium pumps, EM sodium pumps, valves, and instrumentation. Mechanical sodium pumps suffered from pump failures related to pump vibration, flow imbalance among pumps, the supply and speed regulation system, and oil ingress through the upper bearing (Guidez et al. 2008). The EM sodium pumps at FFTF also experienced problems, largely from cavitation erosion at low flow rates (Baumhardt and Bechtold 1987).

Manufacturing defects in valves led to sodium leaks at the Fast Breeder Test Reactor (Guidez et al. 2008). Instrumentation failures at Experimental Breeder Reactor-II, Phenix, and Superphenix were largely compensated for by redundancy in the original instrumentation and control design and the use of substitute instruments (Guidez et al. 2008). 
Appendix B

Lead- (or Lead-Bismuth-) Cooled Fast Reactors Overview 



\section{Appendix B}

\section{Lead- (or Lead-Bismuth-) Cooled Fast Reactors Overview}

The lead- (or lead-bismuth-) cooled fast reactor (LFR) system features the potential for a very high reactor outlet temperature, high power density core, low system pressure, and a fast neutron spectrum. The liquid metal coolant, either lead $(\mathrm{Pb})$ or lead/bismuth eutectic $(\mathrm{Pb}-\mathrm{Bi})$ can use natural convention for heat removal or can be pumped, depending on core power requirements. Some LFR designs for small grids or developing countries, like the Gen4 and SSTAR (small, secure, transportable, autonomous reactor), use a factory-built "battery" or "cassette" design and are optimized for power generation over long periods of time (10-30 years) without refueling.

Potential issues with lead-cooled technologies arise from the solidification of the coolant, which can render the reactor inoperable. Lead is the heaviest of all proposed advanced coolants, making it expensive to pump. Additionally, coolant chemistry can lead to erosion of pump materials. Unlike other advanced designs, mechanical pumps are generally proposed for use in LFRs, because EM pumps have low efficiency moving lead.

Additional active features of LFRs include:

- Reactor control mechanisms - Control rod drive mechanisms are located outside the reactor vessel with rods extending into vessel. The Gen4 Module also includes insertion of boron carbide $\left(\mathrm{B}_{4} \mathrm{C}\right)$ balls into a cavity for shutdown.

- Pumps - Pumping fluids/gas to various reactor systems, depending on the reactor design. The SVBR-100 (Svintsovo-Vismutovyi Bystryi Reaktor) reactor used pumps for primary lead coolant, where other design like the STAR (Secure Transportable Autonomous Reactor) series, BREST-OD300 reactor use natural convection and have no primary coolant pumping.

- Valves - Primarily located outside of reactor vessel.

- Instrumentation and monitoring systems, including system for monitoring dissolved oxygen in lead coolant (used to limit corrosions on structural surfaces by coolant), cover gas monitoring system, and delayed neutron detection.

Literature reviewed indicated that the only lead-bismuth cooled reactors with significant operating experience were the ones installed in Russian Alpha-class submarines and the prototype reactors that supported them - seven submarines and two prototypes (Weaver et al. 2001). Flow measurements were made by electromagnetic devices, but these were unreliable because of calibration shifts; however, a venturi-type flow meter operated successfully for 15 months without calibration drift (Woloshun et al. 2004). 




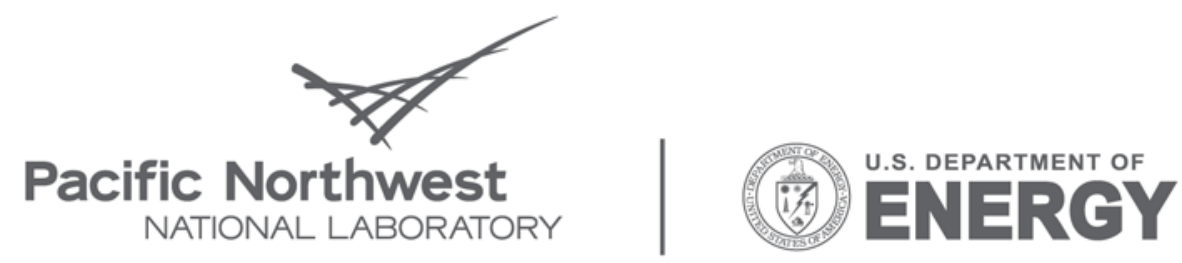

Proudly Operated by Battelle Since 1965

902 Battelle Boulevard

P.O. Box 999

Richland, WA 99352

1-888-375-PNNL (7665)

www.pnl.gov 